\title{
Electrochemical Double Layer Capacitor Electro-thermal Modelling
}

Wasim Sarwar $^{1}{ }^{*}$, Monica Marinescu ${ }^{1}$, Nick Green ${ }^{2}$, Nigel Taylor ${ }^{2}$, Gregory Offer $^{1}$

\author{
${ }^{1}$ Department of Mechanical Engineering, Imperial College London, UK \\ ${ }^{2}$ Hybrids and Electrification Research, Jaguar Land Rover, Warwick, UK \\ * Contact details of corresponding author: \\ w.sarwar@imperial.ac.uk |+44 7894556476
}

Keywords: Ultracapacitor Modelling, High-Fidelity Thermal Model, Internal Temperature Distribution, Electrode Dependent Entropy, Electro-thermal, Temperature Dependant Electrical Model

\section{Highlights}

- An electro-thermal model is created which is valid from $(-) 40 \rightarrow(+) 60^{\circ} \mathrm{C}$

- A peudo-3D thermal model is developed to determine spatial temperature variation

- $\quad$ Electrical equivalent circuit model retains physical meaning

- Differing rates of heat generation are defined for the individual cell constituents

- The temperature gradient between the core of the cell and surface is defined

\section{Abstract}

An electro-thermal model is generated to predict the internal temperature of an Electrochemical Double-Layer Capacitor (EDLC) undergoing high current charging/discharging. The model is capable of predicting the electrical and thermal behaviour of a cell over a wide range of operating conditions. Spiral symmetry is used to reduce the heat generation and transfer model from 3D to a pseudo-3D, which runs faster without losing fidelity.

Unlike existing models, each element in the developed model retains physical meaning and the electrical model is coupled with a high-fidelity thermal model including material geometries, thermal properties and air gaps. Unequal entropy is calculated using first principles, included in the model and compared to experimental data, and shown to be valid. More entropic heat is generated at the positive electrode than the negative in a typical EDLC, and there is little spatial variation of heat generation rate within the jelly-roll.

The heat-transfer model predicts temperature variations within a cell; this study examines these variations for multiple conditions. Whilst undergoing high current charging ( 2 seconds, $400 \mathrm{~A}, 650 \mathrm{~F}$ cell), a temperature gradient in excess of $3.5^{\circ} \mathrm{C}$ can be generated between the positive terminal and the jelly-roll. The time dependent spatial temperature distribution within a cell is explored.

\subsection{Introduction}

Electrochemical Double Layer Capacitors (EDLCs), also commonly referred to as supercapacitors, or ultracapacitors, are energy storage devices which store energy via a physical process of charge separation at the solid/liquid interface. 
They possess high power density, efficiency and cycle life, but low energy density when compared with batteries.

Given their characteristics, EDLCs are ideally suited to applications requiring high power and highly transient loads such as those seen on hybridized passenger and commercial vehicles. Multiple investigations, [1-8], have shown that the addition of EDLCs to batteries in hybridised vehicles reduces the power demanded of the batteries and consequently reduce their temperature rise. This in turn could reduce battery degradation and improve the efficiency of the hybridised energy storage system, [5].

When combining batteries and EDLCs, a large portion of the power demand is met by the EDLCs, therefore they will rise in temperature during operation. Repetitive high current charge and discharge pulses, as are common in the automotive environment, can lead to the formation of temperature gradients where the internal structure of the cell is hotter than the surface of the cell. The performance of EDLCs varies with temperature, particularly at low temperatures,[9]. Consequently, accurate electric modelling of EDLC performance for high currents over extended time periods requires knowledge of the temperature across the active material.

Furthermore, numerous authors,[10-14], have demonstrated that EDLC degradation is highly dependent upon temperature. Faradaic reactions, which are the primary cause of capacitance fade and resistance rise, increase exponentially with temperature, and hence an increase in temperature by $20^{\circ} \mathrm{C}$ typically increases degradation by an order of magnitude, [14] [15].

To determine the temperature variation of a supercapacitor during operation, multiple authors have developed thermal models, which are suitable for a range of applications. For consideration of early cell design, d'Entremont et al [16] have calculated the reversible and irreversible heat generation during electrical operation using a continuum physical electrical model based on the GouyChapman-Stern approximation of double layer. The model therefore defines the non-uniformity of heat generation throughout the active material. However, the study assumes the use of solid carbon planar electrodes rather than highly porous electrodes.

The majority of works are concerned with the study of commercial EDLCs, where the heat diffusion equation is solved in one [17], two [18], or three dimensions [19] [20]. If solving the heat diffusion equation in one direction, heat transfer occurs through the material thickness of contacting materials, directly between the core of the cell and the outer surface of the can; axial temperature gradients (between the terminals of a Maxwell 650F cell) are not considered. If solving in two dimensions, axial temperature gradients can be considered, however the heat transfer around the spiral of the jelly-roll cannot. If solving in three dimensions, the aforementioned limitations are addressed, at the expense of computational cost. The full 3D model developed by Frivaldsky [20] in Comsol can be used to verify the thermal results of reduced order models, (if the temperature changes are not a result of electrical activity). 
The works of Gualous et al [18] experimentally measure the difference in temperature between the core and the surface of a cell during operation, and latterly model the thermal behaviour using a simplified two dimensional heat diffusion equation. These results demonstrate that the core of the cell is hotter than the surface during operation. It must be considered however that the insertion of (non-calibrated) thermocouples into the jelly-roll increases resistance, reduces axial thermal conductivity (some contact welds are missing), reduces radial thermal conductivity (looser winding), and increases the radial temperature gradient between the core and surface of the cell, (via elimination of the air gap between the jelly-roll and can).

The few authors $[17,21]$ who have combined electrical and thermal models to produce electro-thermal models have used lumped thermal models only. The models are capable of providing reasonable estimations of electrical performance and temperature change over a range of electrical and thermal conditions. Berrueta et al [21] develop a temperature dependant electrical model, but ignore thermal gradients. The works of Parvini et al [17] do not constrain parameters within logical limits as their electrical model has a capacitance value 10-15 times greater than the capacitance of the cell. The thermal model is lumped with an assumption of a fourth order polynomial cooling rate radially between the core and can, which does not account for the discontinuity of the air gap between the jelly-roll and can.

This paper will focus upon the development of a coupled electro-thermal model capable of predicting temperature variations throughout a cylindrical cell, and subsequently uses this information on thermal gradients to determine the temperature dependent electrical behaviour.

\subsection{Modelling:}

Nomenclature

\begin{tabular}{|c|c|c|}
\hline Variable & Units & \\
\hline$\alpha$ & ${ }^{\circ} \mathrm{C}^{-1}$ & Temperature coefficient of terminal material \\
\hline $\mathrm{A}, \mathrm{B}, \mathrm{D}, \mathrm{F}$ & & Dimensionless experimentally derived constants from EIS \\
\hline $\mathrm{C}$ & $\mathrm{F}$ & Capacitance \\
\hline$C_{0}$ & $\mathrm{~F}$ & Primary Capacitance \\
\hline$C_{\text {Branch } x}$ & $\mathrm{~F}$ & Capacitance of Branch 'x' \\
\hline$C_{B 1}, C_{B 2}$ & $\mathrm{~F}$ & Capacitance of RC Branch 1,2 \\
\hline$C_{\text {measured }}$ & $\mathrm{F}$ & Measured Capacitance \\
\hline$C_{R}$ & $\mathrm{~F}$ & Re-distribution Capacitance \\
\hline$C_{R C \text { Branch }}$ & $\mathrm{F}$ & RC Branch Capacitance \\
\hline$C_{\text {Transmission_Line }}$ & $\mathrm{F}$ & Transmission Line Capacitance \\
\hline$C_{v}$ & $V^{-1}$ & Voltage proportionality of Capacitance \\
\hline $\mathrm{e}$ & $\mathrm{C}$ & Electron charge \\
\hline I & A & Current \\
\hline $\mathrm{k}$ & $m^{2} k g s^{-2} K^{-1}$ & Boltzmann constant \\
\hline $\mathrm{N}$ & & Number of branches \\
\hline$Q$ & $\mathrm{~J}$ & Heat Generated \\
\hline
\end{tabular}




\begin{tabular}{|l|l|l|}
\hline$R_{\text {Branch }}$ & $\Omega$ & Resistance of branch 'x' \\
\hline$R_{\text {contact }}$ & $\Omega$ & Contact resistance \\
\hline$R_{\text {ionic }}$ & $\Omega$ & Ionic resistance \\
\hline$R_{\text {measured }}$ & $\Omega$ & Measured resistance \\
\hline$R_{\text {Leak }}$ & $\Omega$ & Leakage resistance \\
\hline$R_{\text {series }}$ & $\Omega$ & Series resistance \\
\hline$R_{\text {series }}$ & $\Omega$ & Series resistance at initial temperature \\
\hline $\mathrm{T}, T_{0}$ & ${ }^{\circ} \mathrm{C}$ & Temperature, Initial Temperature \\
\hline $\mathrm{t}$ & $\mathrm{S}$ & Time \\
\hline$\tau$ & $\mathrm{S}$ & Time Constant \\
\hline Th $h_{C C}, T h_{E l}, T h_{\text {Sep }}$ & $J \mathrm{Kg}^{-1}{ }^{\circ} \mathrm{C}^{-1}$ & Thermal Mass of current collector, electrode, separator \\
\hline$S_{\text {dl }}$ & $\mathrm{J}^{\circ} \mathrm{C}^{-1}$ & Entropy of double layer \\
\hline $\mathrm{V}$ & $\mathrm{V}$ & Voltage \\
\hline$v_{0}, v_{H}$ & $\mathrm{~m}^{-3}$ & $\begin{array}{l}\text { Volume occupied by the electrolyte in the uncharged state, and } \\
\text { charged state (Helmholtz layer thickness). }\end{array}$ \\
\hline $\mathrm{x}$ & & RC Branch Number \\
\hline Subscript & $\mathrm{Units}$ & \\
\hline+ & & In relation to the positive ion \\
\hline- & & In relation the negative ion \\
\hline $\mathrm{CC}$ Thick & & Current Collector Thickness \\
\hline El_Axial & & Electrode in the y-direction \\
\hline El_Spiral & & Electrode in the x-direction \\
\hline El_Thick & & Electrode Thickness \\
\hline $\mathrm{i}$ & & Denotes the turn number within the spiral of the jelly-roll \\
\hline $\mathrm{j}$ & & Denotes the discretisation unit number in the y-direction \\
\hline $\mathrm{n}$ & & Denotes the number of turns of the spiral of the jelly-roll \\
\hline $\mathrm{m}$ & & Denotes the number of discretisation units in the y-direction \\
\hline Sep_Thick & & Separator Thickness \\
\hline $\mathrm{x}$ & & Denotes RC branch number \\
\hline
\end{tabular}

Table 1: Nomenclature table

\subsection{Overview}

The electro-thermal model consists of three distinct yet coupled models; an electrical model, a heat generation model and a heat transfer model. The electrical model, (a physically meaningful equivalent circuit), simulates the flow of charge through the system and determines the voltage response of a cell for a given current input. It defines the currents and resistances used as an input for the heat generation model.

The heat generation model defines the quantity and distribution of the generated thermal energy due to ionic activity and ohmic losses in the electrical conductors. The physical heat transfer model determines the temperature change across the spatially discretised cell, in which different discretisation units are characterised by their geometric and thermal properties. Appropriate boundary conditions are set. The local temperature is an input into the electrical model and it has a direct effects capacitance, internal resistance and contact resistance.

\subsection{Heat Transfer Model}




\subsubsection{Background}

Cylindrical EDLC cells comprise a wound jelly-roll within an aluminium can, where the positive current collectors are welded to one side, and the negative to the other. The jelly-roll consists of sheets of carbon electrodes, aluminium current collectors and paper based separators which are wound in a spiral; these are arranged as depicted below in Figure 1. In this particular cell, (Maxwell K2 Series 650F), the jelly-roll is measured to be $5 \mathrm{~m}$ long and is wound into a spiral consisting of 42 turns, with an outer diameter of $56 \mathrm{~mm}$.

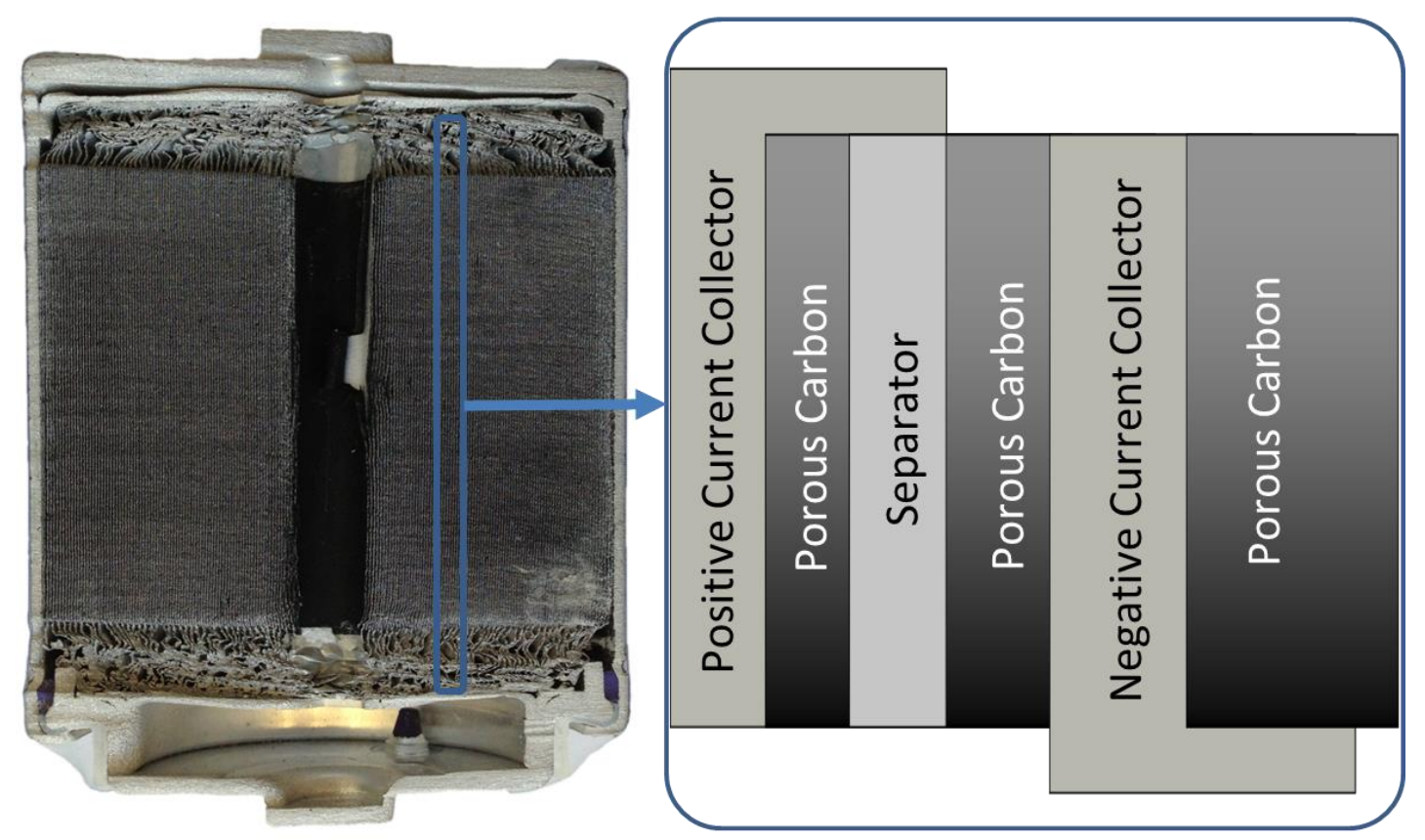

Figure 1: Image of cross section of a Maxwell 650F cell, including an illustration (not to scale) of the repeating element within the jelly roll

\subsubsection{Model description}

To predict the temperature distribution across a cylindrical EDLC, a pseudo-3D heat transfer model is developed. The cell is divided into unit areas, and the geometric and thermal properties are defined using an equivalent thermal circuit analogy.

Each material has a defined thermal capacity and thermal resistance in the $x, y$ and $z$ directions; Figure 2 graphically illustrates the manner in which this is distributed across the jelly-roll. The nomenclature for directional heat-transfer in this paper is defined as:

- $\quad X$-direction: Heat transfer around the spiral in a given material.

- $\quad Y$-direction: Axially lengthwise between the terminals of the cell in a given material.

- $Z$-direction: Radially across the thickness of the jelly-roll, between different materials.

Each turn of the spiral is discretised individually, and further split into ' $n$ ' segments along the Y-direction of the jelly-roll. As shown in Figure 2, each unit cell of the jelly-roll can conduct in the $x$ and/or $y$ directions to adjacent unit cells, 
or in the case of current collectors at the ends of the cell, into the terminal materials. Each unit cell can also conduct heat in the $z$ direction, through the intermediate layers, which can be represented as a thermal short-circuit through the jelly-roll rather than around it. Heat-transfer in the $z$-direction through different materials is treaded as per the $x$ and $y$ direction, with varying material geometry and properties for each layer. This is graphically illustrated in the lower portion of Figure 2. It is assumed that the interface between materials does not introduce an additional thermal resistance; the model was found to be insensitive to the use of this assumption as the heat transfer in the $z$-direction is dominated by the low thermal conductivity of porous carbon.

Unit cells increase in width in the $x$-direction from the core to the edge of the jelly-roll because each $x$-direction discretisation consists of one turn of the spiral, and each turn of the spiral results in a progressively larger diameter. For the outer turns of the jelly-roll, where the unit cells are relatively long in the $x$ direction, heat transfer across the layers (in the $z$-direction), can be appreciable relative to heat transfer around the jelly roll (in the $x$-direction) despite the higher thermal conductivity of the materials in the $x$ and $y$ directions. For the inner turns of the jelly-roll, heat transfer in the $x, y$ direction around the jelly roll is dominant compared to through the layers, as the unit cells are now relatively short in the $x$ direction. By discretizing with unit cells with variable $x$ length and thermal short-circuits representing heat transfer between layers it is possible to model 3D temperature gradients in a straightforward way. Unlike the thermal model developed by Gualous et al, [22], heat transfer is considered in each direction, the heat transfer rate is dependent upon the geometric and thermal properties of each material, and crucially the air-gap between the jelly-roll and aluminium can is accounted for. This approach makes use of spiral symmetry to prevent the high computational cost associated with a fully discretised 3D model. 


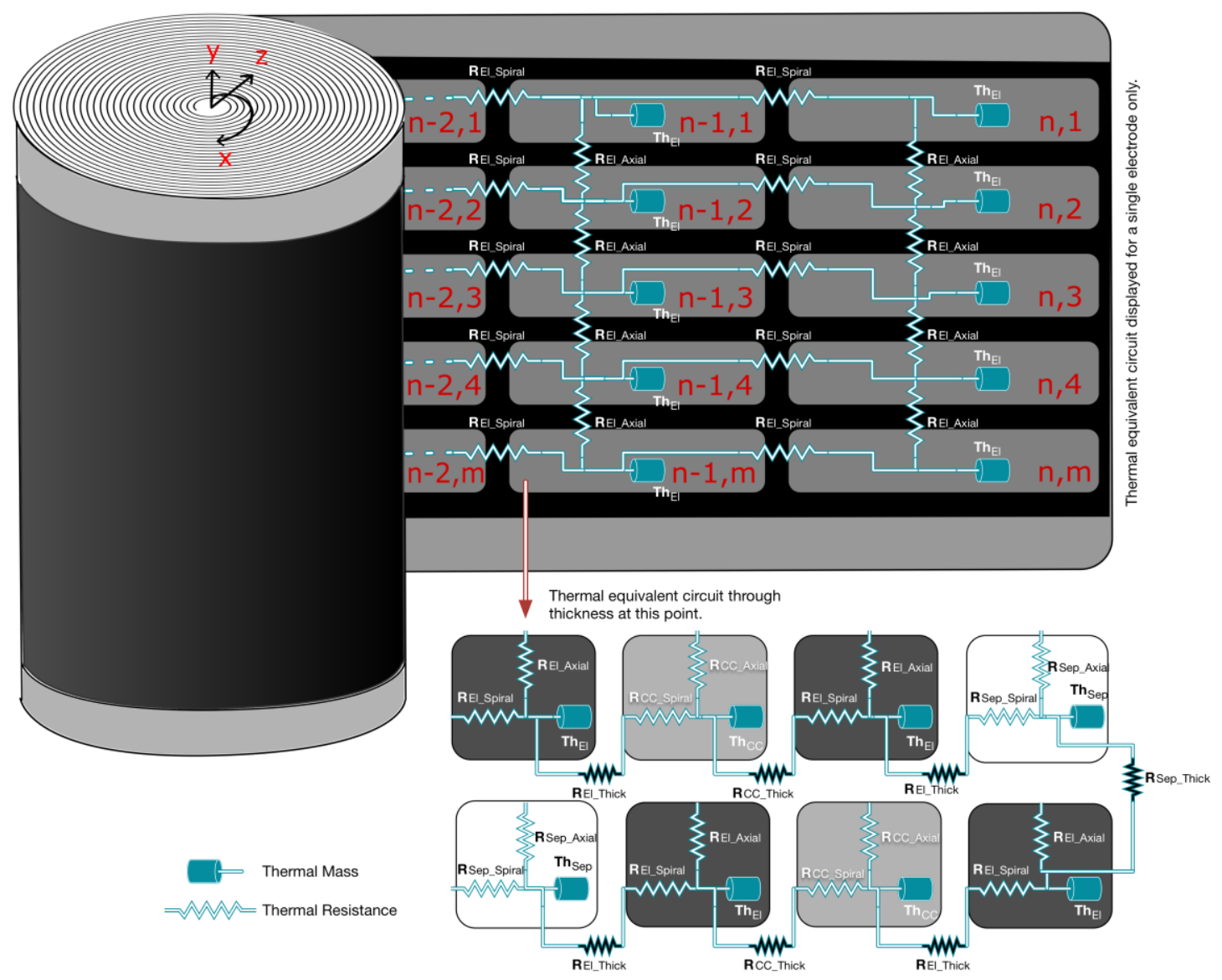

Figure 2: Illustration of the structure and discretisation of the jelly-roll in the developed pseudo-3D thermal model - [Top] Partially unwound jelly-roll with grey blocks illustrating the thermal model discretisation [for ' $n$ ' $x$ ' $m$ ' elements] and a thermal equivalent circuit showing the thermal resistance and capacitance through a single electrode only, [Bottom] Illustration of the thermal connection between material layers, (heat transfer in the $\mathrm{Z}$ direction), in the jelly roll at discretisation segment $(n-1, m)$ via a thermal equivalent circuit.

There are two mechanisms for heat transfer between the system and the surroundings: conduction from the jelly-roll through the current collectors and further to the cell terminals, and convection, across the air gaps at the centre and outer boundary of the jelly-roll.

\subsection{Electrical Model}

\subsubsection{Model Structures}

Numerous authors have constructed models to predict the electrical behaviour of EDLCs that can broadly be categorised as either physical models [23-25] or equivalent circuit models, [16,26-31] . Although the physical models provide us with more information about the phenomena occurring within the cell, these models remain relatively immature, and to date, no model has provided validated results over a complex drive cycle. Lajnef et al, [29], developed a generic equivalent circuit model for an EDLC as shown in Figure 3a, and demonstrated that it reproduced EDLC behaviour reasonably well over long time periods whilst at a constant temperature. Devillers et al, [31], compares the accuracy of multiple electrical models over a period of 700 seconds at different temperatures, and confirms the findings of Lajnef et al. For this study, good 
reproduction of electrical behaviour over complex drive cycles is necessary, therefore an equivalent circuit model is favoured over a physical model.

The generic model in Figure 3a can be simplified to the very basic form seen in Figure $3 \mathrm{~b}$ for frequencies between $1 \mathrm{mHz}-10 \mathrm{~Hz}$ and time periods $<500 \mathrm{~s}$. The author found that a single transmission line and a single RC branch can provide good voltage matching over transient loads and provide a good estimate for charge-redistribution for a particular time period, whilst being relatively simple to parameterise. A cell utilising porous electrodes has many time constants, thus for longer model operational time it is necessary to utilise additional RC and transmission line branches.

The transmission line branches model the available capacitance for a given resistance to adsorption, which is analogous to the ion adsorption path tortuosity, [32]. Each RC branch has a time constant that relates to the rearrangement of ions; charge re-distribution is a non-linear process, hence the greater the number of RC branches utilised, the lower this discrepancy will be, at the trade-off of greater complexity. A detailed description of the correlation between electrical circuit elements and the physical processes occurring within the cell during operation has been complete by numerous authors, $[15,21,33]$. The following works study the effect of transmission line length, [15], and the the number of RC branches, [34]. 

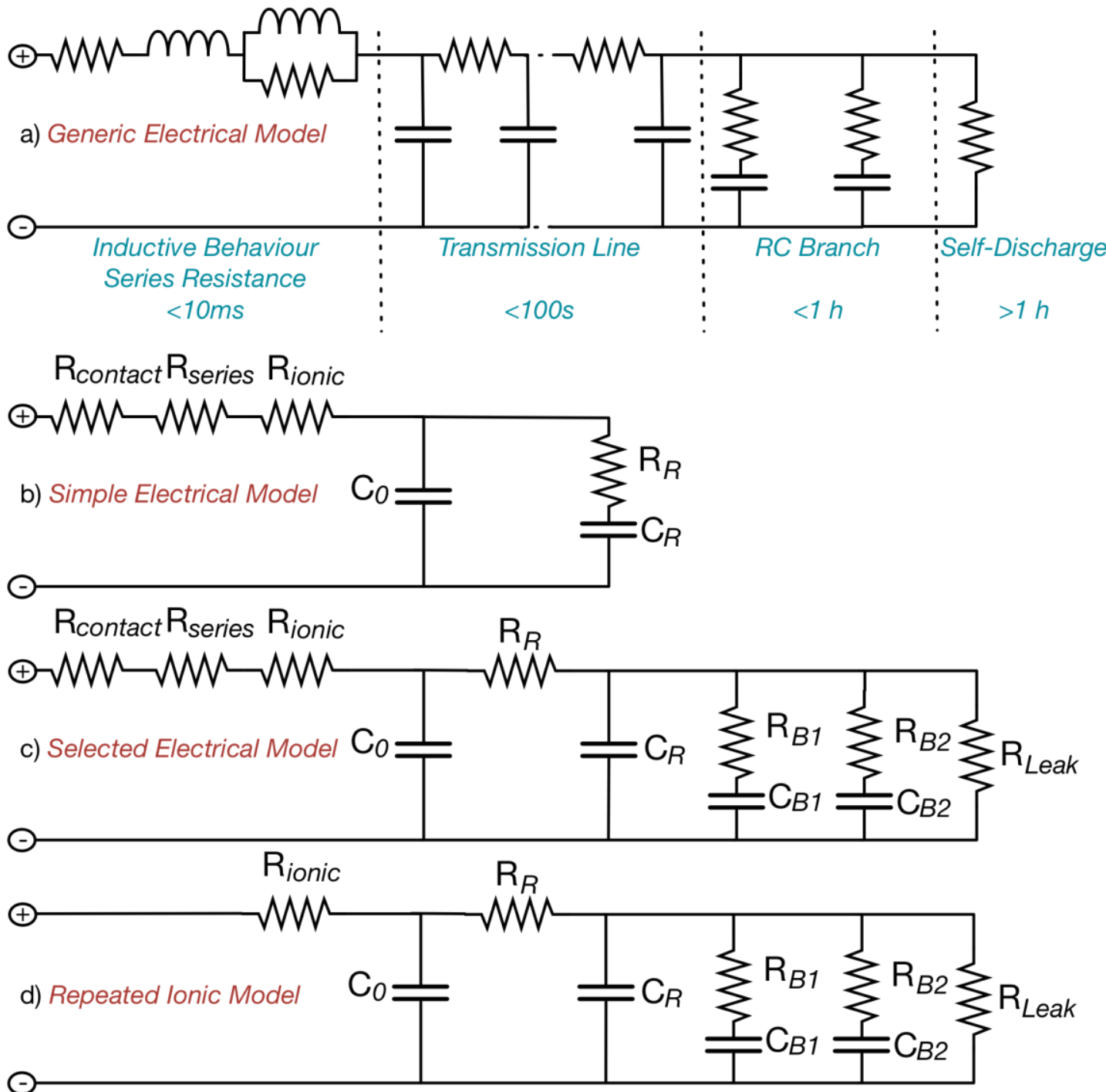

Figure 3: [a] A generic electrical equivalent circuit model which has been discretised by time domain for the electrical modelling of an EDLC - adapted from Lajnef [33] [b] Highly simplified electrical equivalent circuit model, [c] Selected model to be used during electrical parameterisation, [d] Repeated ionic unit used within semi-physical high fidelity model.

Figure 4 shows the evolution of the constituents of a pore within the electrode from an uncharged state to a fully charged state, and their representation in the model. Following the elapse of time period $\mathrm{T}_{1}$, the initial charge of the transmission line is complete, however counter-ions and solvent molecules remain trapped within the pore. Given continuation of charging, the charge saturation of the pore will increase, with different stages of charge saturation being associated with increasing time constants of an RC branch. 


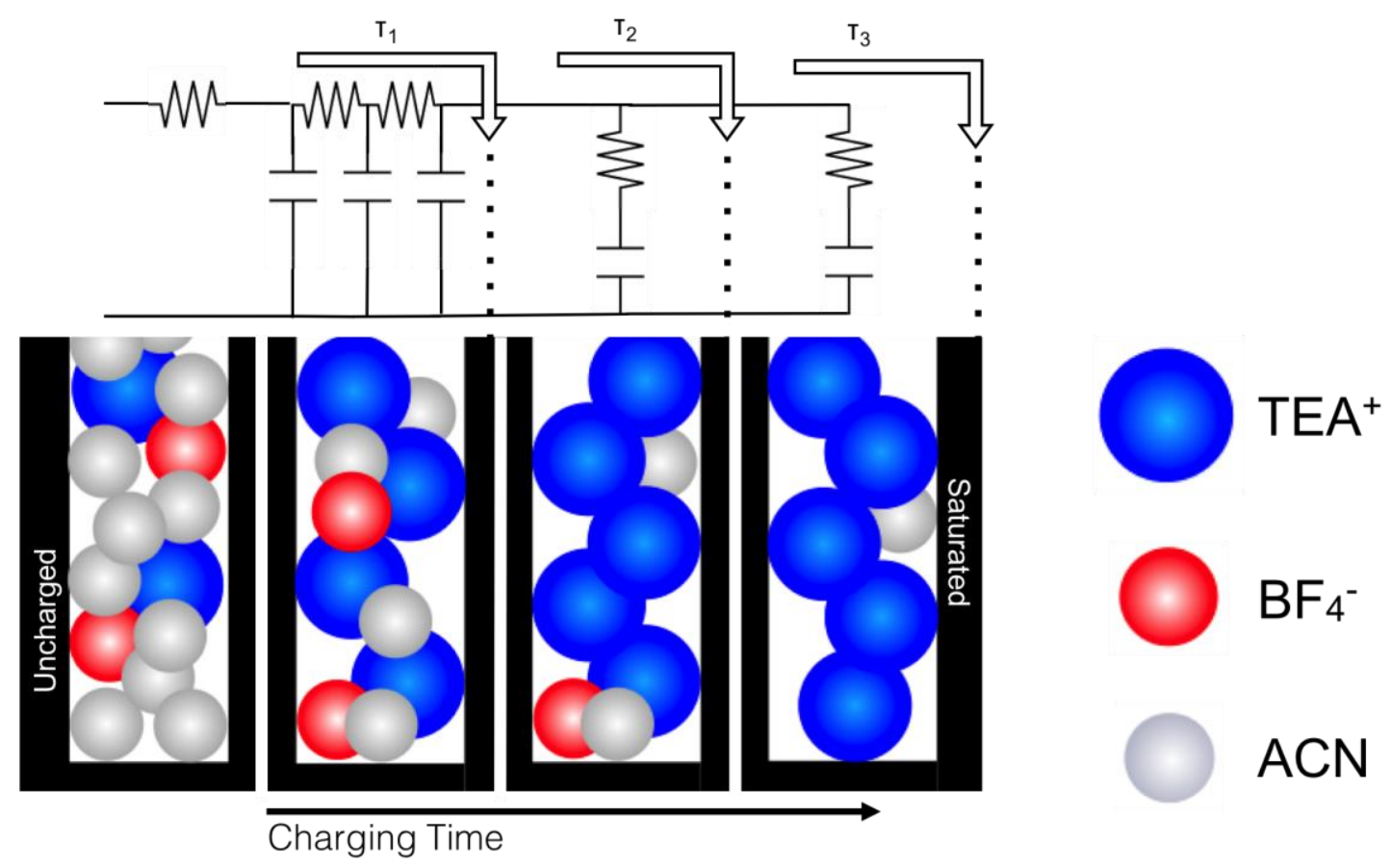

Figure 4: Illustration aligning the transmission line ( $\tau 1)$ and the RC Branches ( $\tau 2 \& \tau 3)$ with different degrees of charge saturation within a carbon pore. Illustrations depecit findings of [35-37]

The number of RC branches required to re-produce cell behaviour depends upon the time period of interest, and the accuracy required. Additionally, it is desirable to minimise the number of model parameters for consistency and

reproducibility. The model shown in Figure 3c provides sufficient accuracy for the scope of this study over a broad range of conditions upto an operation time of 1500 s, as shown in the model validation section.

Although electrical equivalent circuit models are capable of predicting the voltage response of EDLCs very accurately, the existing electrical cell models are empirical models and therefore cannot spatially define electrical activity and hence heat generation. Therefore, the use of a single electrical equivalent circuit model with lumped resistances, such as that seen in Figure 3c, with a highly detailed thermal model necessitates the assumption of uniform volumetric heat generation. However, due to differing current paths and internal temperature gradients, the electrical activity, and hence rate of heat generation could vary throughout the cell. Consequently, it is necessary to create an electrical model that accounts for localised electrical activity throughout the cell, which can be used to determine whether the heat generation model must be distributed or lumped.

The equivalent circuit model in Figure 3c can very accurately recreate the voltage response of an EDLC, as shown in the model validation section. Therefore it is adapted to create a semi-physical high fidelity EDLC electrical model, illustrated in Figure 5. The model describes the electrical resistance path and spatial ionic activity of the cell using resistor networks and repeated equivalent circuits. The connections between the electrodes mimic ionic activity; each connection is via the repeated ionic circuit illustrated in Figure 3d. The 
electrodes are discretised into ' $m$ ' axial segments, (between the electrodes $/ y$ direction), and ' $n$ ' radial segments, (each turn of the spiral jelly roll $/ x$-direction).

A reduced schematic of the electrode resistor networks used to model the current collectors and electrodes is shown in Figure 5. Electrical resistances for the current collector and carbon are given as a function of the material resistivity and geometry. In the rolled jelly-roll, the matching node co-ordinates marked on the electrodes will form a locally flat electrode pair between which ionic movement can take place. The positions of nodes for ionic connection are shown on the resistor networks and the ionic connection between the resistor networks are illustrated in Figure 5. Each node is marked with co-ordinates $(i, j)$, where $i$ denotes the number of the turn within the spiral of the jelly roll, and $j$ denotes the distance in element numbers away from the positive terminal, where each element is an equal fraction of the distance between the positive and negative terminals. Each ionic connection is made via the electrical circuit shown in Figure $3 d$, where its positive connection connects to $(x, y)$ on the positive electrode, and its negative terminal connects to $(x, y)$ on the negative terminal.

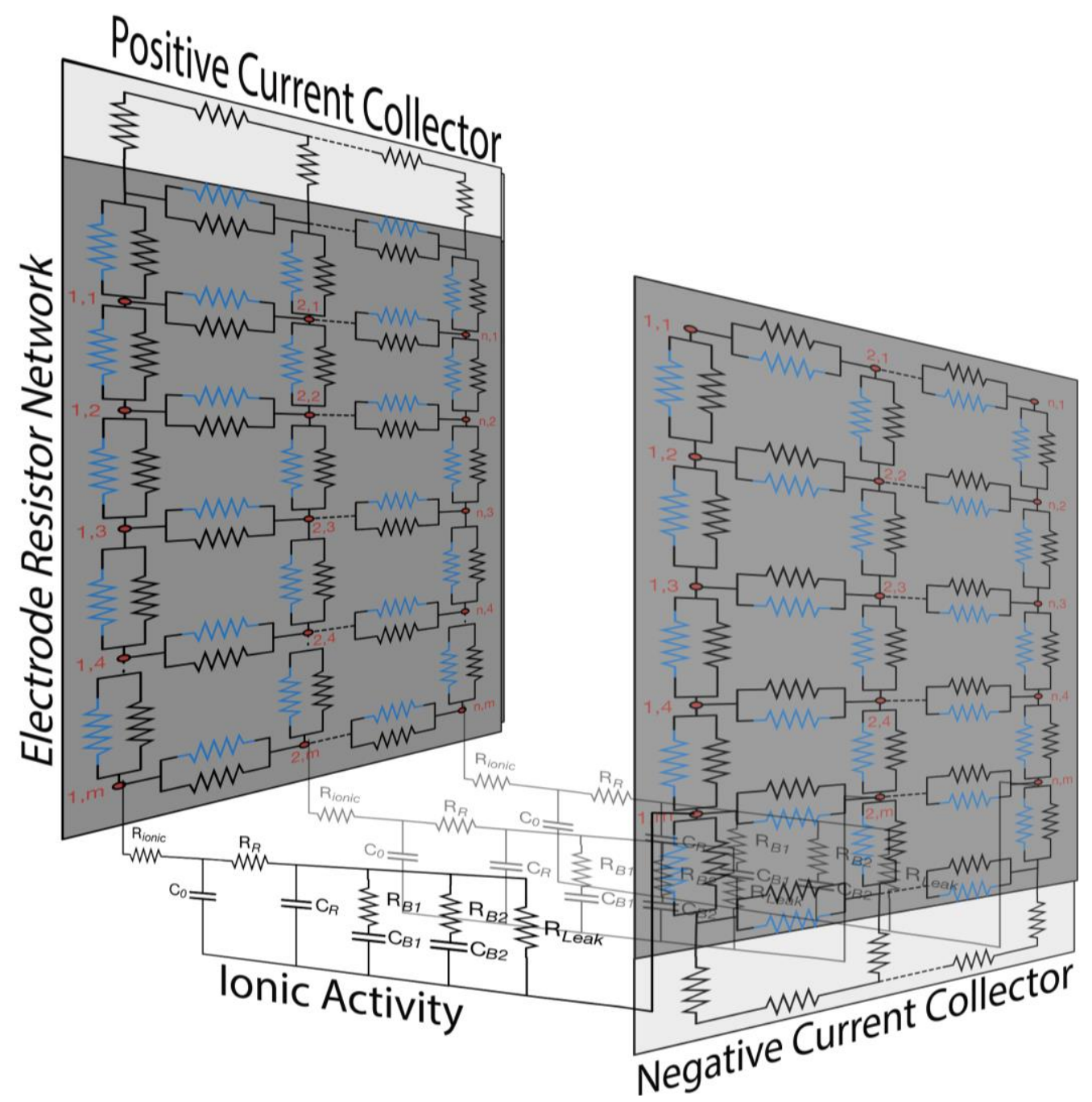

Figure 5: Reduced schematic of high fidelity semi-physical electrical model. The positive and negative electrode resistor networks are connected at nodes via a repeated electrical circuit which is shown to connect coordinates $(1,5)$ and $(2,5)$ on the positive and negative electrodes. 


\subsubsection{Parameter variation with operating conditions}

The resistance and capacitance of EDLCs are affected significantly by cell voltage, operating temperature, charge/discharge frequency and operating current, [15]. Each of these variations affects the process of double layer formation, which lies at the basis of EDLC function.

Starting with a discharged cell, upon the application of a potential difference between the positive and negative terminals of the cell, the electrodes become either electron rich or electron deficient. This gives rise to the formation of electric fields around the electrodes that attract counter-ions available in the electrolyte and repel co-ions. Counter ions accumulate at the electrode surfaces to balance that charge. The electrons from the electrode, and the ions from the electrolyte are now held in position by a strong electric field between their opposing charges. The electrical energy applied to the cell is thus converted into potential energy in the form of electrostatic attraction.

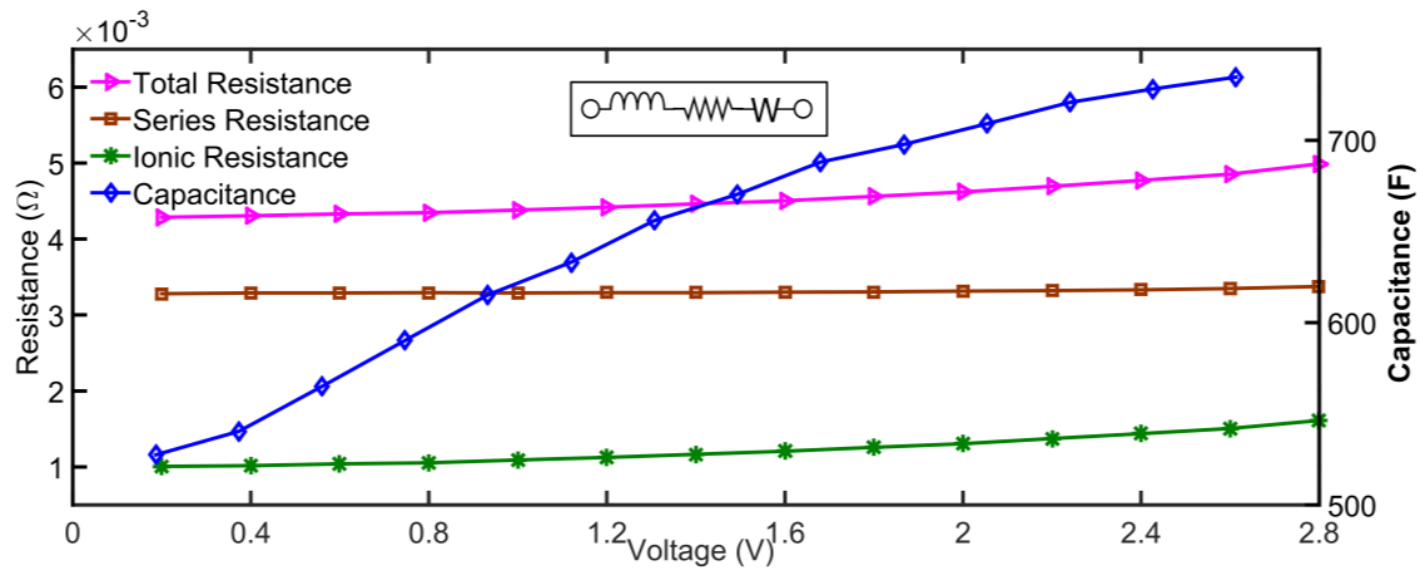

Figure 6: Capacitance \& resistance variation of a Maxwell BCAP0650 cell with voltage

A change in the cell voltage results in an increase of both the capacitance and resistance of the cell as shown in Figure 6. The capacitance of the cell increases significantly and non-linearly with voltage, typically by $50-80 \%$ for a change in voltage of $2.7 \mathrm{~V}$. An increase in the cell voltage results in a decrease in the charge separation distance at the electrode/electrolyte interface, thereby increasing the electrostatic force of attraction. Consequently, the potential energy that can be stored in the double layer is increased, as is the cells' ability to store charge. This effect can be approximated with a linear increase in capacitance with voltage, [38].

It is possible to distinguish the series and ionic resistance of a supercapacitor through fitting of EIS data to a simple equivalent circuit, as seen in the inset of Figure 6, consisting of a series string of an inductance, a series resistance and Warburg element, [39]. The series resistance represents all of the bulk material and interface resistances hindering electron flow, whilst the ionic resistance (resistive element of the Warburg element) relates to the restriction of ion movement as a result of separator and electrode porosity, electrolyte resistivity and concentration dependant tortuosity. Consequently, the series resistance 
does not vary with voltage, however the ionic resistance increases because the diffusion resistance increases due to larger ion path tortuosity.

\subsubsection{Variation with Temperature}
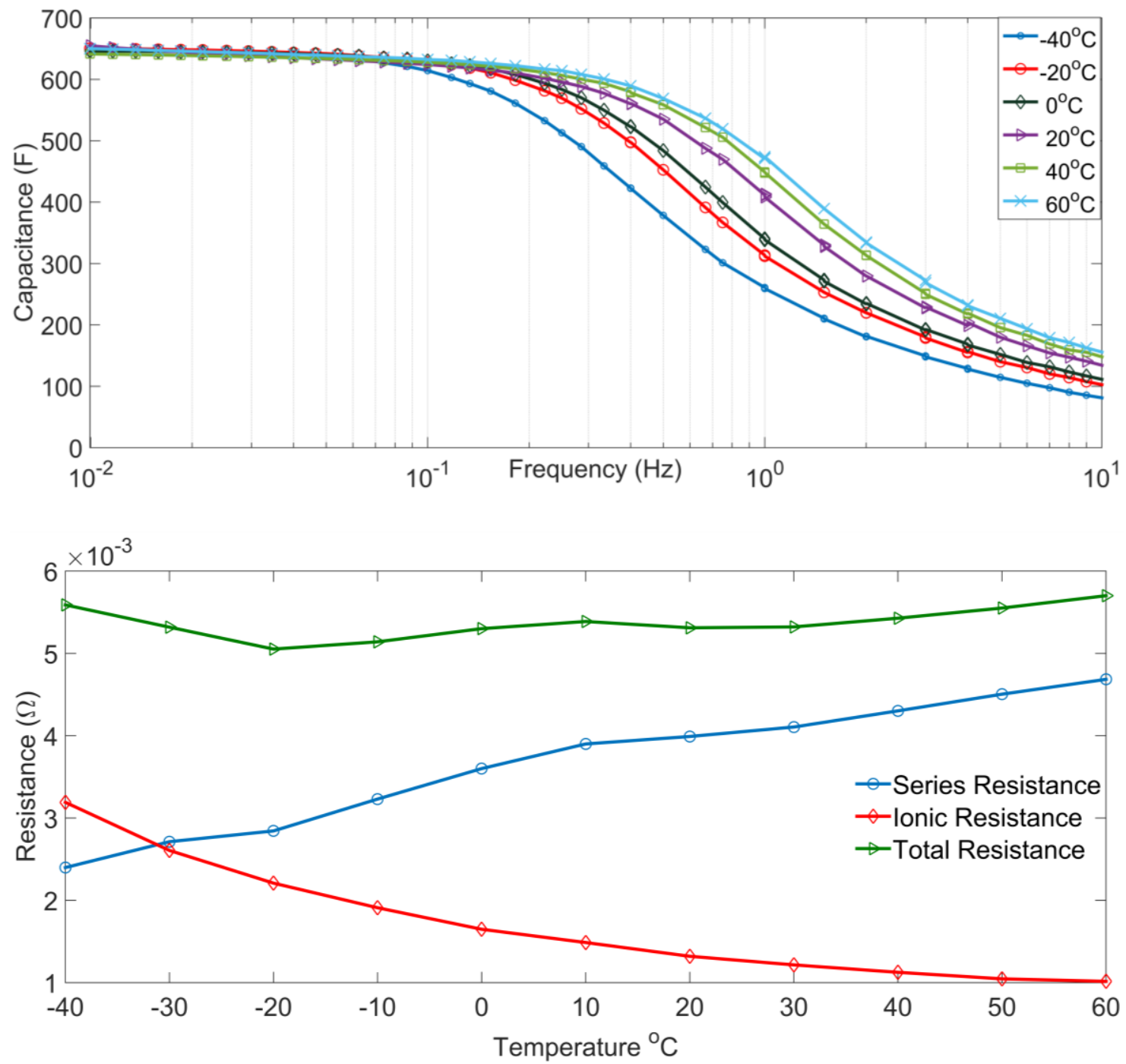

Figure 7: Measured capacitance \& resistance variation of a Maxwell BCAP0650 cell with temperature

Whilst the capacitance of a cell is independent of temperature at very low frequencies, it is highly temperature dependant at higher frequencies where capacitance is diffusion limited. The capacitance at low temperatures is lower due to the reduced mobility of ions. At $1 \mathrm{~Hz}$, the capacitance is $80 \%$ greater at $60^{\circ} \mathrm{C}$ compared with $-40^{\circ} \mathrm{C}$. Higher temperatures assist ion diffusion and reduce electrolyte viscosity, and hence effectively increase the accessible surface area when capacitance is diffusion limited. This is evident from the higher capacitance and lower ionic resistance at higher temperatures, as shown in Figure 7.

For this particular cell, the total resistance varies little with temperature, however both the series and ionic resistance vary significantly. It is worth noting that larger capacitance cells which retain the same form factor, (simply increase 
in length between the terminals), have a larger ionic to series resistance ratio. The series resistance, which is made up of electrical conductors, increases linearly with temperature. Conversely, the ionic resistance follows an Arrhenius relation and decreases with an increase in temperature due to an increase in electrolyte conductivity, and thus reduced diffusion resistance, [15].

\subsubsection{Variation with Current}

The variation of capacitance with current can be calculated by using the below formula with a constant current and consistent voltage limits,

$$
C=\frac{I \cdot \mathrm{dt}}{V_{\max }-V_{\min }}
$$

where $\mathrm{C}$ is the capacitance $(\mathrm{F}), \mathrm{I}$ is the current $(\mathrm{A}), \mathrm{V}$ is the voltage $(\mathrm{V})$ and $\mathrm{t}$ is the time (s).

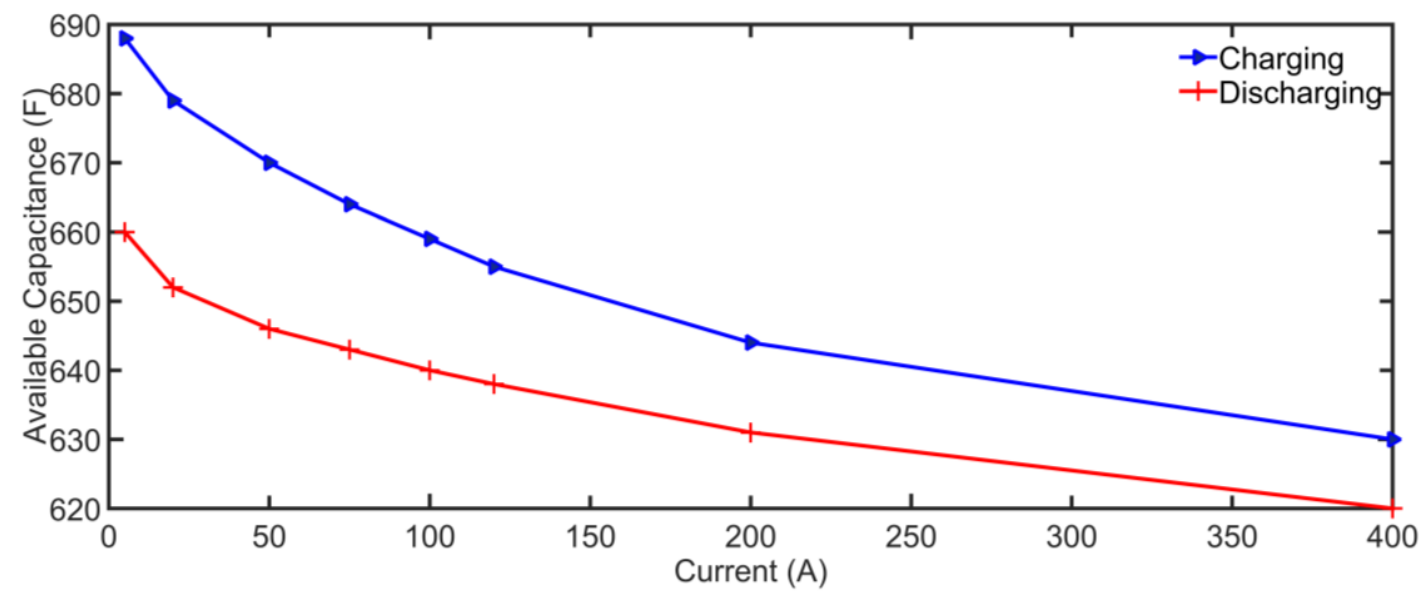

Figure 8: Available capacitance variation with applied current, measured during both a charge and discharge

The accessible capacitance of the cell changes with current, as less of the electrode surface area can be utilised over a shorter time period. Additionally, we observe a difference in the measured capacitance over a charge and a discharge. This occurs as the calculation is based upon measured cell voltage, and the measured voltage is not necessarily the voltage at all points within the cell. The easily accessible electrode surfaces will charge or discharge first; the more difficult to access surfaces will initially lag behind and eventually balance with the remainder of the cell. This phenomenon has been termed the residual charge effect $[28,40]$, and is the cause of charge re-distribution. When charging, the measured cell voltage is slightly greater than the real voltage, whilst when discharging, the measured voltage is slightly lower than the real voltage. The true or equilibrium charge and discharge capacitance are almost identical.

The steady state and dynamic capacitance of the cell are not equal; the dynamic capacitance (due to the residual charge effect) will tend to the highest applied current. 


\subsection{Model Parameterisation}

\subsubsection{Electrical Model}

The electrical model parameters are estimated using data acquired from Electrochemical Impedance Spectroscopy (EIS), and constant current charge and discharge curves. These parameter values are subsequently refined within tight boundaries using the Simulink parameter estimation toolbox. The parameters used in this model can be found in Table 2 .

\subsubsection{Capacitance}

The measured capacitance is defined in the model as:

$$
C_{\text {measured }}=C_{\text {Transmission_Line }}+C_{R c \text { Branch }}
$$

where the transmission line capacitance, $C_{\text {Transmission Line }}$, is analogous to the capacitance of the easily accessible part of the porous structure, whereas the capacitance of the RC branches, $C_{R C \text { Branch }}$, is analogous to the capacitance of the difficult to access regions of the porous structure. The ease of access to the porous structure and the required adsorption energy vary based upon the tortuosity of the ions path to adsorption.

The transmission line capacitance is equal to the measured capacitance at the highest current of interest. Further, the transmission line capacitance is split into two capacitances, $C_{0}$, and $C_{R}$ each of which has a voltage proportionality, $C_{v}$.

$$
C_{\text {Transmission_Line }}=\left(C_{0}+\left(C_{0} \cdot C_{v} \cdot V\right)\right)+\left(C_{R}+\left(C_{R} \cdot C_{v} \cdot V\right)\right)
$$

Where $C_{0}$ is the primary capacitance and is the capacitance measured at zero volts, which can be determined by backwards extrapolation of the capacitance curve in Figure 6, and inspection of the y-intercept. $C_{v}$ is the capacitance voltage proportionality factor, and $C_{R}$ is the re-distribution capacitance, which is typically $10 \%$ of $C_{0}$.

Given equations ( 2 ) and Error! Reference source not found., it is possible to determine the RC branch capacitance from experimental data. However, the capacitance of each branch depends upon the number of branches, and the time period of interest. As an initial estimate, it is therefore suitable to distribute this capacitance equally between the branches. The optimisation algorithm refines the value.

\subsubsection{Resistance}

The measured resistance is implemented in the model as:

$$
R_{\text {measured }}=R_{\text {series }}+R_{\text {ionic }}
$$

The series resistance varies linearly with temperature as shown in Figure 6, hence can be given by:

$$
\Delta R_{\text {series }}=R_{\text {series }_{0}}\left(1+\alpha\left(T-T_{0}\right)\right)
$$


where $\Delta R_{\text {series }}$ is the temperature dependant change of series resistance $(\Omega)$, $R_{\text {series }_{0}}$ is the resistance at the initial temperature $(\Omega), \alpha$ denotes the temperature coefficient of terminal material $\left({ }^{\circ} \mathrm{C}^{-1}\right), T$ is the temperature of terminal $\left({ }^{\circ} \mathrm{C}\right)$ and $T_{0}$ is the starting temperature of terminal $\left({ }^{\circ} \mathrm{C}\right)$.

The ionic resistance varies with an Arrhenius relation with temperature, and also varies with SOC, hence is given by:

$$
R_{\text {ionic }}=\left(A V^{2}+B V+D\right) \exp (F / T)
$$

Where $A, B, D$ and $F$ are dimensionless experimentally derived constants from EIS.

The RC branch resistance, $R_{R C \text { Branch }}$, is the resistance associated with the adsorption occurring in the high-energy/difficult to access adsorption areas.

The resistance to ion flow in these areas is significantly higher than that of easily accessible areas, however the former contributes little to the measured resistance of the cell as there is little activity in these regions. As such, equation ( 4 ) should include $R_{R C \text { Branch }}$ with a weighting factor determining its contribution to $R_{\text {ionic }}$ as a function of the current through the RC branches. In reality, the current passing through the RC branches is difficult to quantify without a model, hence the calculated values of $R_{\text {series }}$ and $R_{\text {ionic }}$ are overestimates and are used in the parameter optimisation as maximum values. The time constant of the redistribution branch, $\tau_{R}=C_{R}$. $R_{R}$, must correspond to the time required to discharge the cell from its maximum SOC, to minimum SOC at the maximum current that the model is valid for.

The resistance of the $\mathrm{RC}$ branches is determined by:

$$
R_{\text {Branch } x}=\frac{(x / N) \cdot t_{\text {Limit }}}{C_{B r a n c h} x}
$$

where $R_{B \text { ranch } x}$ is the resistance of branch $x$ in RC branch $x, x$ is the branch number, $\mathrm{N}$ is the number of branches and $t_{\text {Limit }}(s)$ is the period of model validity, upto a maximum of one hour.

\begin{tabular}{|l|l|l|l|}
\hline Parameter & Value (F) & Parameter & Value $(\mathbf{\Omega})$ \\
\hline $\mathrm{C}_{0}$ & 500 & $\mathrm{R}_{\text {contact }}$ & $3.76 \mathrm{e}-5$ \\
\hline $\mathrm{C}_{\mathrm{V}}$ & 0.105 & $\mathrm{R}_{\text {ionic }}$ & $3.84 \mathrm{e}-4$ \\
\hline $\mathrm{C}_{\mathrm{R}}$ & 47.0 & $\mathrm{R}_{\text {series }}$ & $2.41 \mathrm{e}-4$ \\
\hline $\mathrm{C}_{\mathrm{B} 1}$ & 21.8 & $\mathrm{R}_{\mathrm{R}}$ & $2.43 \mathrm{e}-2$ \\
\hline $\mathrm{C}_{\mathrm{B} 2}$ & 12.3 & $\mathrm{R}_{\mathrm{B} 1}$ & $6.32 \mathrm{e}-1$ \\
\hline & & $\mathrm{R}_{\mathrm{B} 2}$ & 49.86 \\
\hline & & $\mathrm{R}_{\text {leakage }}$ & $9.47 \mathrm{e}+5$ \\
\hline
\end{tabular}

Table 2: Parameter values used in electrical model for Maxwell $650 \mathrm{~F}$ Cell at $25^{\circ} \mathrm{C}$

\subsubsection{Thermal Model Parameterisation}

The parameters for the thermal model were taken from literature, and are shown in Table 3. 


\begin{tabular}{|c|c|c|c|}
\hline Material & $\begin{array}{l}\text { Specific Heat } \\
\text { Capacity } \\
\left(\boldsymbol{K} \boldsymbol{K g}^{-1} K^{-1}\right)\end{array}$ & $\begin{array}{l}\text { Thermal } \\
\text { Conductivity } \\
\qquad\left(W K^{-1} m^{-1}\right)\end{array}$ & References \\
\hline Aluminium Can & 898 & 205 & [41] \\
\hline $\begin{array}{l}\text { Aluminium } \\
\text { Current Collector }\end{array}$ & 898 & 205 & [41] \\
\hline $\begin{array}{l}\text { Carbon Electrode } \\
\text { (wet) }\end{array}$ & 700 & 0.47 & [42] \\
\hline $\begin{array}{l}\text { Separator (Paper } \\
\text { Based) (wet) }\end{array}$ & 1340 & 0.22 & [43] \\
\hline Polypropylene & 1700 & 0.12 & [43] \\
\hline Air & 1005 & 0.02 & [41] \\
\hline
\end{tabular}

Table 3: Material properties for the parameterisation of the thermal model

\subsection{Heat Generation Model}

\subsubsection{Heat Quantification}

The heat generated within a supercapacitor can be categorised as either reversible or irreversible. The 'reversible heat' is due to changes in the arrangement of ions between the charged and uncharged states, and hence, changes in entropy. Schiffer et al [44] define the entropy of each double-layer for a monovalent electrolyte within the cell as:

$$
S_{d l}=\frac{k C V}{e} \ln \left(\frac{v_{H}}{v_{0}}\right)
$$

Where $S_{d l}$ denotes the entropy of the double layer $(J / K), v_{H}$ is the volume of the Helmholtz layer $\left(\mathrm{m}^{-3}\right), v_{0}$ is the electrolyte volume, $\left(\mathrm{m}^{-3}\right)$, $\mathrm{k}$ is the Boltzmann constant $\left(\mathrm{m}^{2} \mathrm{kgs}^{-2} \mathrm{~K}^{-1}\right)$, and e is electron charge (C).

The underlying assumption is that the double layer is solely formed of a Helmholtz layer; a single layer of ions perfectly balances the charge on the electrode, the thickness of the double layer does not vary and is equal for both electrodes. The work of Schiffer et al [44] and Gualous et al [18] demonstrate that these assumptions remain valid for a highly microporous cell when assuming homogenous heating within the cell. Whilst the works of d'Entremont et al [16] indicate that the entropy at the positive and negative electrodes differs when the electrolyte contains dissimilar ions, to the best knowledge of the author, no works have shown the difference in the entropic heat generated at the positive and negative electrodes. The entropy at each electrode is calculated in order to assess the heat generation within the cell.

Assuming the size of the double layer does not change with time, the entropy change with respect to time is:

$$
\frac{\mathrm{d} S_{d l}}{\mathrm{~d} t}=\frac{k C}{e} \ln \left(\frac{v_{H}}{v_{0}}\right) \frac{\mathrm{d} V}{\mathrm{~d} t}
$$

And the corresponding generation heat rate: 


$$
\frac{\mathrm{d} Q_{\text {reversible }}}{\mathrm{d} t}=-T \frac{\mathrm{d} S_{d l}}{\mathrm{~d} t}
$$

Substituting equation ( 9 ) into ( 10 ), and using, $\frac{\mathrm{d} V}{\mathrm{~d} t}=\frac{I(t)}{C}$, an expression for the reversible heat generated at the positive and negative electrodes can be obtained:

$$
\begin{aligned}
& \frac{\mathrm{d} Q_{\text {reversible }_{+}}}{\mathrm{d} t}=-\frac{T k}{e} \ln \left(\frac{v_{H_{-}}}{v_{0}}\right) I(t) \\
& \frac{\mathrm{d} Q_{\text {reversible }_{-}}}{\mathrm{d} t}=-\frac{T k}{e} \ln \left(\frac{v_{H_{+}}}{v_{0}}\right) I(t)
\end{aligned}
$$

The electrolyte typically utilised within commercial supercapacitors is Tetraethylammonium terafluoroborate, $\left(T E A B F_{4}\right)$, where the de-solvated positive ion $\left(T E A^{+}\right)$is $42 \%$ larger than the negative ion $\left(B F_{4}{ }^{-}\right),(0.68 \mathrm{~nm}$ vs $0.48 \mathrm{~nm}$ ). Consequently, inserting values into equations ( 11 ) and ( 12 ), it is calculated that approximately $40 \%$ more entropic heat is generated at the positive electrode.

'Irreversible heat' generated within the cell is a result of losses due to electronic resistances within the solid phase and ionic resistances in the liquid phase. The irreversible heat generated is expressed as:

$$
\frac{\mathrm{d} Q_{\text {irreversible }}}{\mathrm{d} t}=\sum_{j=1}^{n} R_{x}(T) I(t)^{2}+I(t)^{2} R_{\text {contact }}(T)
$$

where $R_{x}$ is the resistance of branch 'x' $(\Omega)$.

It is assumed that chemical reaction heat can be neglected when operating the cell within the manufacturer's defined operating conditions.

\subsubsection{Heat Location}

The heat generated across the contact resistances is equally applied to the positive and negative terminals. The heat generated as a result of the series resistance within the cell is split between the carbon electrodes and aluminium current collectors. The electrical resistance of the carbon is two orders of magnitude greater than the resistance of the aluminium, therefore it is assumed that $99 \%$ of this heat is generated within the electrodes, and $1 \%$ within the aluminium elements. The entropic heat and heat generated as a result of ionic resistance are distributed throughout the electrodes and separator.

\subsection{Electro-thermal Model Configuration}

The constructed electro-thermal model consists of a heat transfer model, a heat generation model and an electrical model. Above, multiple electrical models are presented in Figure 3 and Figure 5. The semi-physical high-fidelity electrical model presented in Figure 5 enables the heat generation model to locally define 
heat generation at each discretisation of the thermal model. However, it is significantly more computationally expensive than the use of the model presented in Figure 3c, which uses an assumption of uniform volumetric heat generation within a given material. Therefore, it would be highly desirable to make this assumption if possible.

To determine whether this assumption is valid, the spatial current density variation through the jelly-roll was examined with the use of the semi-physical high-fidelity electrical model. Figure 9 shows that dissimilar current paths through the jelly-roll lead to a variation in the current density, which will subsequently lead to spatial variations of the heat generated within the jelly-roll. However, the difference is small; for a 75A discharge starting at a uniform temperature of $20^{\circ} \mathrm{C}$ the total charge delivered between $0-14$ seconds shows a maximum spatial difference of $1.4 \%$, (with the greatest current density toward the radial core and axial extremities, i.e. $(1,1) \&(1,5))$. These regions have the highest current density because they have the shortest resistance paths.
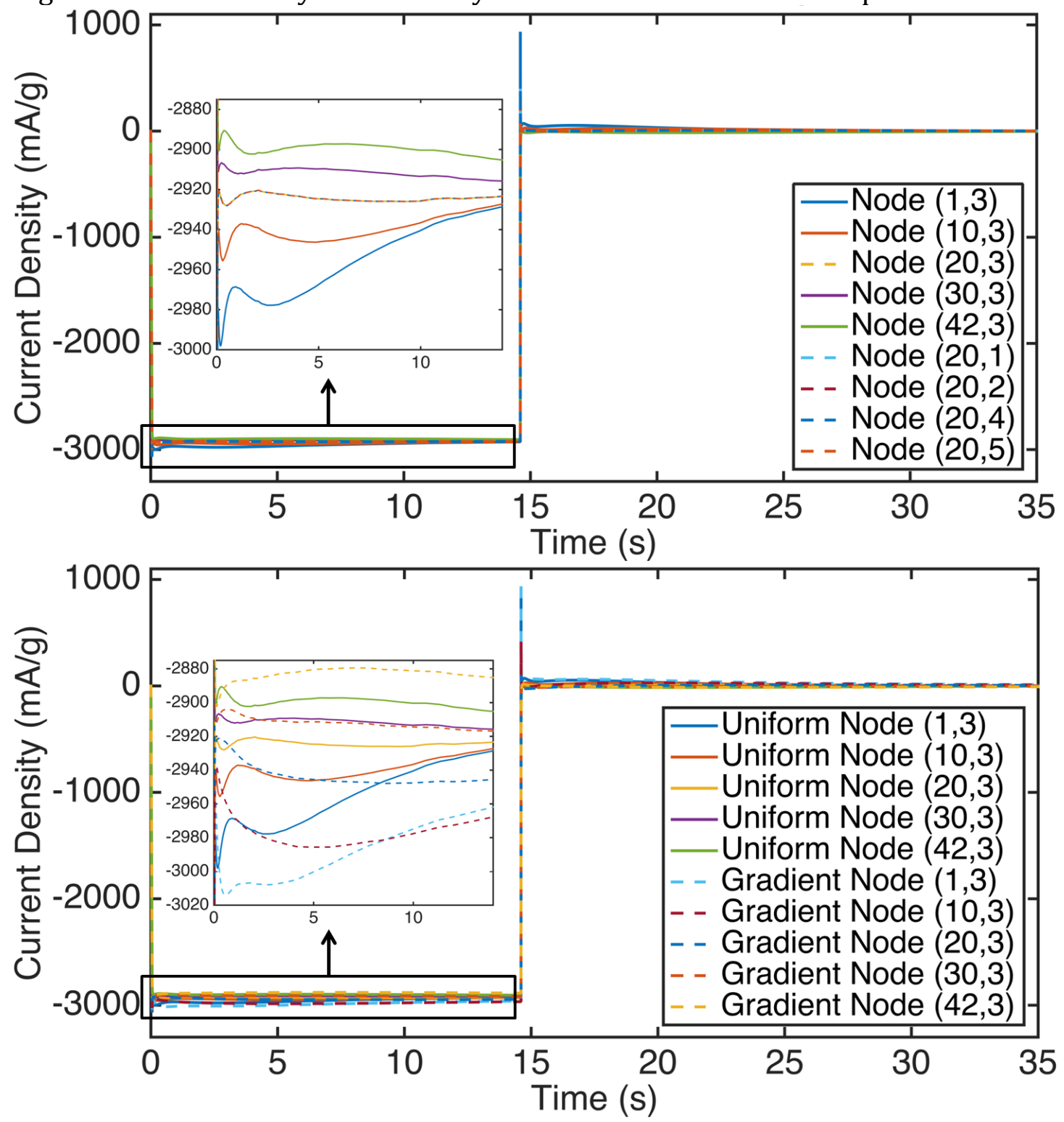

Figure 9: [a] Spatial current density variation through the jelly-roll whilst at a uniform temperature of $20^{\circ} \mathrm{C}$ during a 15 second 75A discharge - Top. [b] Radial current density variation through jelly-roll of non-uniform 
temperature during a 15 second 75A discharge. An artificial radial temperature gradient of $6 \mathrm{~K}$ between the core and edge of the jelly-roll was applied - Bottom.

However, given that active material resistance will change with temperature, it is known that an existent temperature gradient enhances current density imbalance; this is shown in Figure 9b. Artificially imposing a constant temperature gradient of $6^{\circ} \mathrm{C}$ from the core to the edge of the jelly roll yields a maximum spatial difference in charge delivered of $3 \%$.

Gualous et al [18] measured the radial temperature variation through a cell, and for an applied current of $15 \mathrm{~A}$ found a temperature gradient of $6^{\circ} \mathrm{C}$ between the can and the core of the jelly-roll, though the thermal gradient within the jelly-roll did not exceed $2^{\circ} \mathrm{C}$. The thermal gradient found by Gualous et al is likely to be an overestimate due to the elimination of the air-gap between the jelly-roll and can during the insertion of thermocouples. The cell used by Gualous et al for these measurements has a volume of approximately a third and resistance 7 times greater than the cell used in this study, (Maxwell 650F). This study is interested in higher currents, therefore a value of a maximum temperature gradient of $6^{\circ} \mathrm{C}$ across the jelly-roll was assumed to be a reasonable assumption.

Given the small deviations in charge delivered by different regions of the jellyroll, and hence small differences in heat generation, it was determined that it was reasonable to assume uniform volumetric heat generation in a given material. Consequently, the electrical equivalent circuit model in Figure $3 \mathrm{c}$ is utilised in conjunction with the heat transfer model in Figure 2 and the described heat generation model to form the electro-thermal model.

\subsection{Experimental}

Charging and discharging of the cell is conducted using a Biologic HCP-1005 potentiostat with a $100 \mathrm{~A}$ booster for currents upto 100A, and a Bitrode MCV for currents above this. EIS was conducted in galvanostatic mode with current amplitude of $3 \mathrm{~A}$ using a Biologic BCS-815 potentiostat. For uniform temperature testing, an ESPEC BPL-3 thermal chamber was used.

Precise and accurate data was required for the thermal validation of the electrothermal model. The following measures were taken to improve the quality of the data acquired:

- To reduce measurement error - Class 1 type $\mathrm{T}$ thermocouples were attached to the cell using a very thin layer of electrically isolating, yet thermally conductive epoxy; this reduced the electrical noise in the signal. Relative temperatures are used to reduce thermocouple error from $1 \mathrm{~K}$ to $0.02 \mathrm{~K}$.

- To prevent convection of heat to environment - To prevent the distortion of the thermal profile due to heat transfer by convection to the environment, the cell was wrapped in insulation (Rockwool) of very low, and known thermal conductivity.

- To control conduction to environment - The cables connecting the cell to the cell cycler act as large heat-sinks. To reduce heat transfer into these cables, a heating element was attached to the cables, with a PID controller aiming to match the temperature of the cables to the temperature of the cell. 


\subsection{Results and Discussion}

\subsection{Electrical Model Validation}

A current profile was developed to test the quality of the voltage estimation of the simple electrical model as seen in Figure $3 \mathrm{~b}$. A very good fit was achieved, with the maximum error occurring during the charge re-distribution process, most notably a short duration after a high current charge or discharge. The maximum error in the estimated voltage is $2 \%$.

At times greater than 200 seconds, the voltage error of the simple model (Figure $3 \mathrm{~b}$ ) increases to $12 \%$ on the drive cycle seen in Figure 10c, therefore the model of increased complexity (Figure 3c) is used for all subsequent work in this paper.
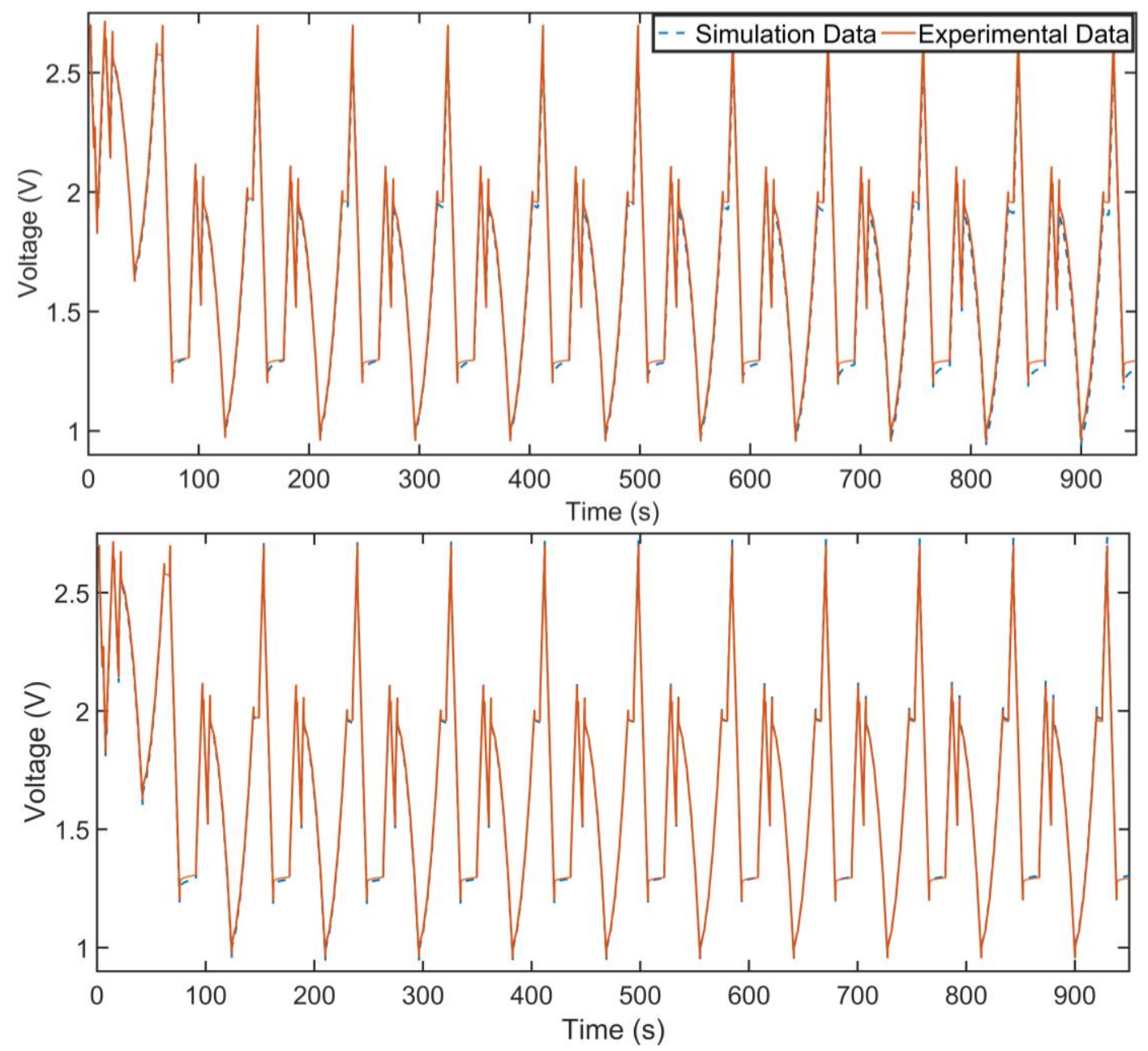


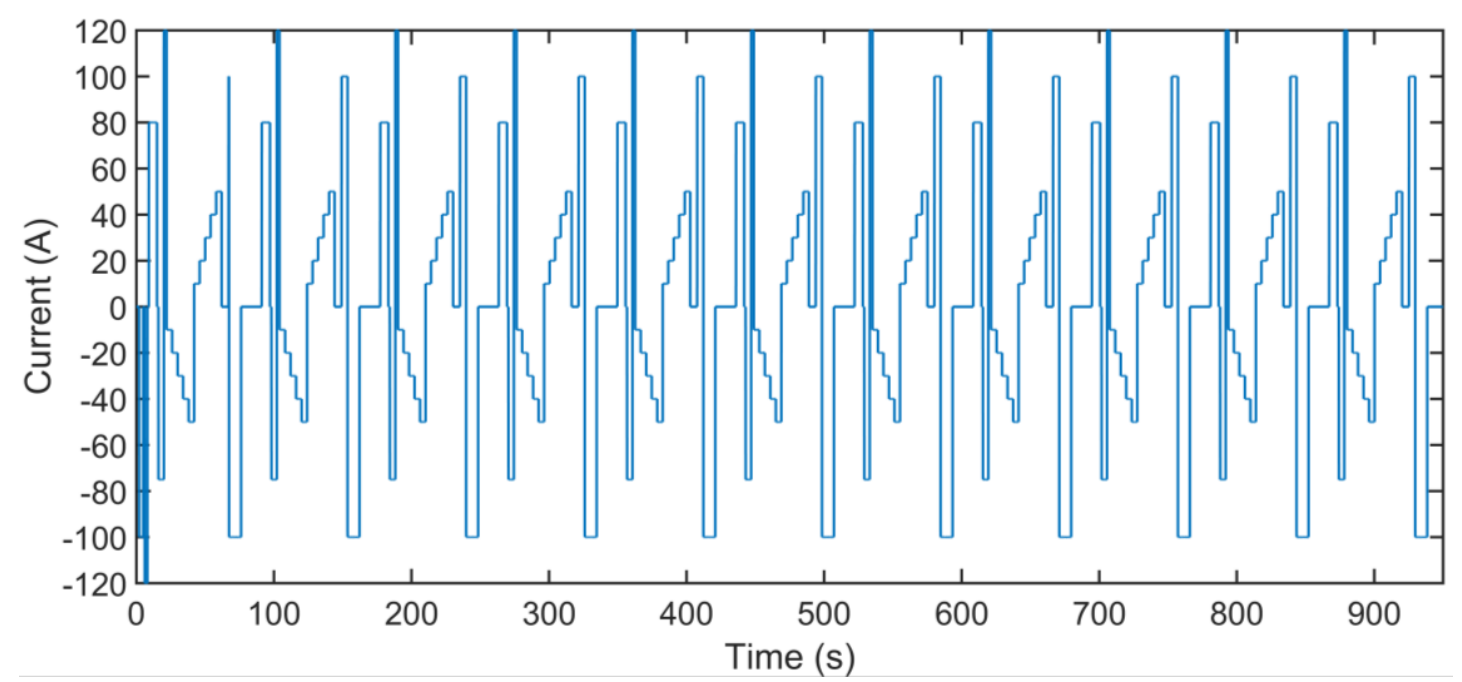

Figure 10a (Top) - Comparison of measured and simulated voltage of a Maxwell 650F EDLC over a highly transient load-cycle, using the complex model seen in Figure $3 \mathrm{c}$ with a constant temperature.

Figure 10b (Middle) - Comparison of measured and simulated voltage of a Maxwell 650F EDLC over a highly transient load-cycle, using the complex model seen in Figure $3 \mathrm{c}$ with an updating jelly-roll temperature.

Figure 10c (Bottom) - Current profile used for simulation in Figure 10a and Figure 10b.

For validation of the electrical element of the electro-thermal model, a transient drive cycle, seen in Figure 10c, is used to test the performance of the electrical model. This validation cycle has been developed to incorporate high and low currents, charges and discharges, different rates of change of current and different switching frequencies to test the model over an array of conditions. Figure 10a shows the voltage response of the complex electrical model (seen in Figure 3c) when operated at a constant temperature, whilst Figure 10b shows the voltage response when the electro-thermal model accounts for temperature changes because of electrical activity. The surface temperature rise over this cycle is $5^{\circ} \mathrm{C}$, and thus resistance decreases with time.

If a constant temperature is input into the electrical model, as seen in Figure 10a, the model will not account for the decreasing resistance, and thus the error will increase with increase with time and temperature rise. The maximum error at a time of less than 200 seconds is $2 \%$. This error increases with time and by the end of the simulation at 950 seconds, the maximum error has increased to $4.3 \%$. Figure $10 \mathrm{~b}$ shows the voltage response where temperature change is accounted for. The resistance now changes with time, therefore the error does not increase with simulation time. The maximum error is stable at $2 \%$ and does not increase with time or temperature difference.

\subsection{Thermal Model Validation}

In real systems, temperature can only be measured at the surface of a cell, however it is mostly the temperature of the jelly roll which affects the performance and degradation of the cell. Therefore, it is desirable to understand the relationship between the surface temperature and the jelly-roll temperature. It is however useful to validate the model by examining the temperature change whilst charging and discharging over a range of conditions by examining surface 
locations. Initially, it is useful to examine the temperature change at a single surface location over a range of loading conditions, and latterly, to include other locations into the analysis.

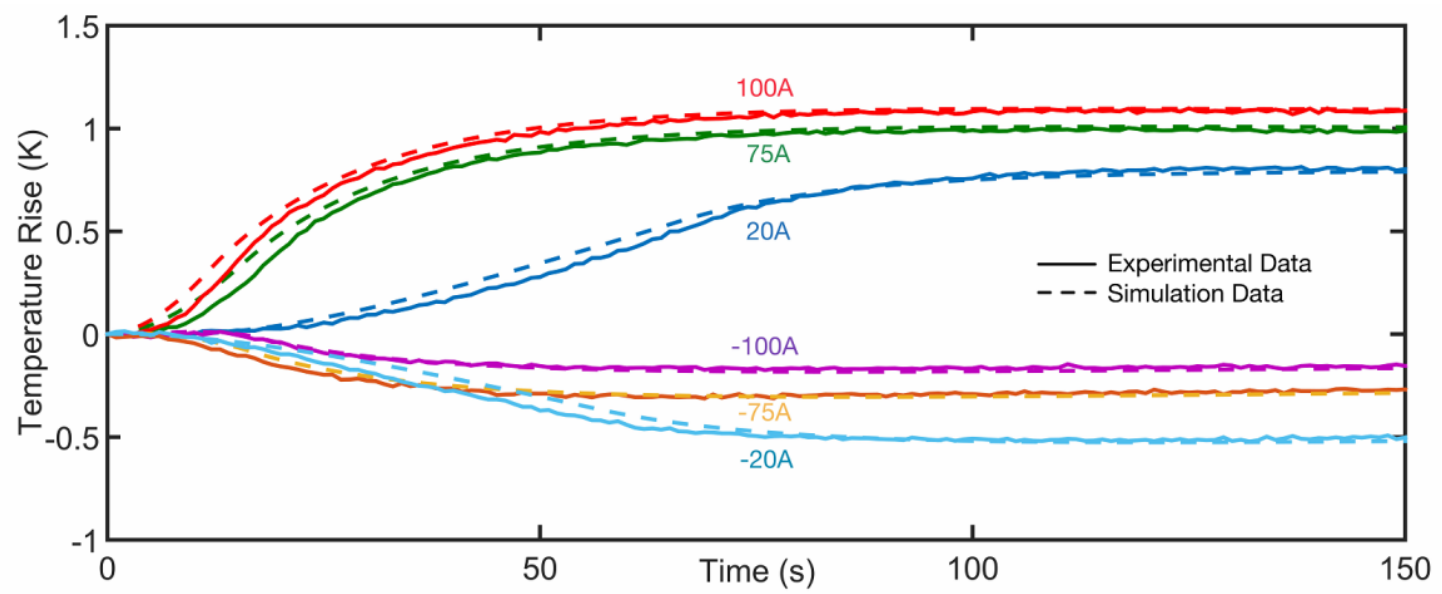

Figure 11: Temperature rise at the positive terminal for charge and discharge events from 20-100A

Figure 11 compares the simulated and experimentally derived temperature change at the positive terminal when the cell is charged or discharged between 0.1-2.7V. It demonstrates that the model provides a very good estimate for the total temperature evolution at the positive terminal for each charge or discharge event tested. Small discrepancies exist for up to 20 seconds for large current charges, and for up to 60 seconds for the small current discharges. The quality of fit, and location of maximum error in the simulated result is very similar at the negative terminal.

\subsection{Predicted Internal Temperature}

The thermal model allows the study of the coupling between the thermal and electrical properties of the cell, and its impact upon performance. For example, a detailed internal temperature map can be obtained for any electrical load.

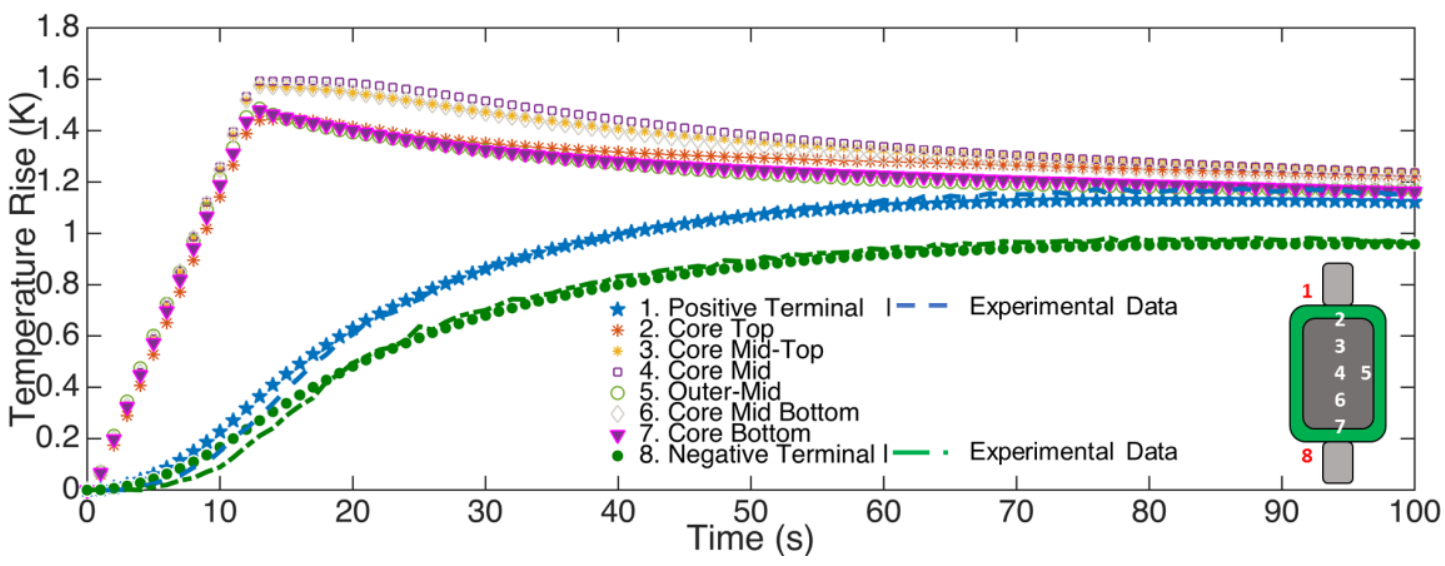

Figure 12: Predicted temperature distribution within a cell during and following a 100A charge from 0.1-2.7V

Figure 12 shows the model predictions of temperature evolution for various positions in the $y$-direction between the terminals, (during a constant current charge at $100 \mathrm{~A}$ from $0.1-2.7 \mathrm{~V}$ ). Surface temperature measurements are shown 
for the positive and negative terminal; as in Figure 11 an excellent fit is achieved with the maximum error occurring at time periods of $<20$ s. The maximum instantaneous temperature difference between the core of the jelly-roll and the surface of the cell is $1.23 \mathrm{~K}$, (341\% higher at core). The maximum temperature reached by the centre of the jelly-roll is $0.5 \mathrm{~K}(46 \%)$ higher than the maximum temperature reached by the surface. The maximum temperature difference between the centre and outer edge of the jelly-roll is $0.1 \mathrm{~K},(6.2 \%$ cooler than the core). Table 4 shows the surface and core temperature differences for a range of currents. Following a 400A charge, the temperature gradient between the core and surface of the cell is in excess of 3.5K. Taking the surface temperature rather than the core temperature will induce an error of up to $6 \%$ in the resistance value, and up to $15 \%$ in the capacitance value. Whilst the duration of this error is limited to the period during which a thermal gradient is present, the errors will accumulate over time.

\begin{tabular}{|c|c|c|c|}
\hline \multirow{2}{*}{$\begin{array}{c}\text { Charging } \\
\text { Current }\end{array}$} & \multicolumn{2}{|c|}{$\begin{array}{c}\text { Maximum Predicted } \\
\text { Temperature (K) }\end{array}$} & $\begin{array}{c}\text { Maximum Predicted } \\
\text { Temperature Difference (K) }\end{array}$ \\
\cline { 2 - 4 } & Surface & Jelly Roll & \\
\hline $75 \mathrm{~A}$ & 0.97 & 1.36 & 0.99 \\
\hline $100 \mathrm{~A}$ & 1.09 & 1.59 & 1.23 \\
\hline $400 \mathrm{~A}$ & 2.91 & 4.01 & 3.89 \\
\hline
\end{tabular}

Table 4: Maximum cell temperature and maximum temperature difference for charging currents from 75-400A

Following periods of activity, thermal gradients form within the jelly-roll. Figure 13 shows the radial and axial thermal gradients between the core and the surface of the cell following the charge event at 1700s in Figure 14. There is little temperature variation $(3 \%)$ in the radial direction due to the air gap between the outer surface of the jelly-roll (radial distance of $28 \mathrm{~mm}$ from core) and the inner surface of the aluminium can (radial distance of $30 \mathrm{~mm}$ from core). The axial temperature gradient (5\%) is only slightly larger than the radial temperature gradient; however the axial temperature gradient is expected to be larger for longer cells, typically higher capacity cells within a product range, $[45,46]$. The core is $16 \%$ hotter than the surface in this particular test.
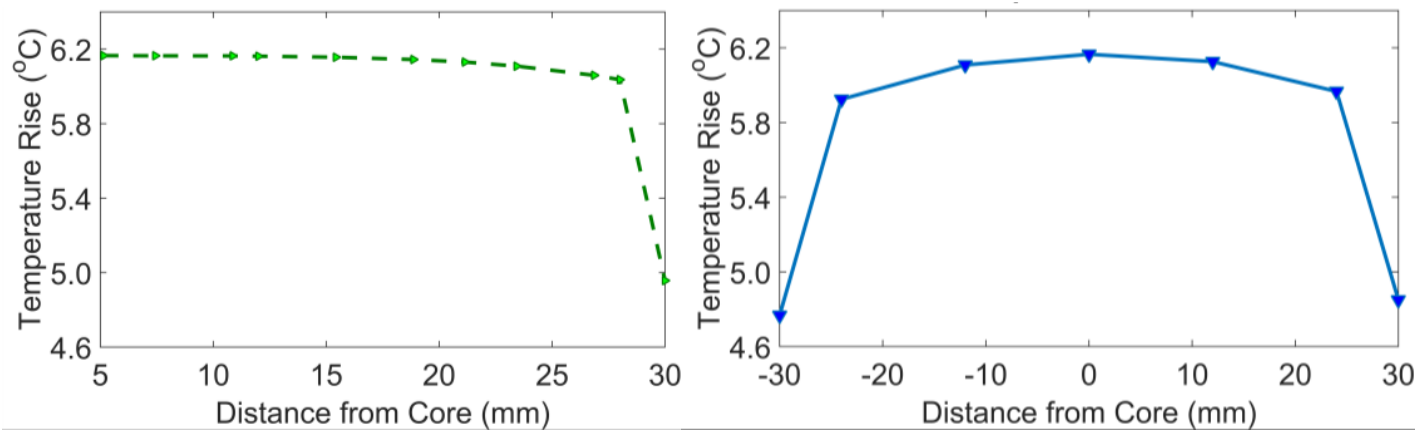

Figure 13: Predicted radial (left) and axial (right) temperature distributions in the cell from the core to the surface - Presented data taken following 1700 s of continuous charging and discharging at $50 \mathrm{~A}$ with natural convective cooling. 
It is shown in Figure 14 that following a period of continuously charging and discharging the cell at $50 \mathrm{~A}$ between $1.2-2.7 \mathrm{~V}$, the predicted temperature at the positive and negative terminals of the cell matches the experimental data very well. The maximum error $(0.3 \mathrm{~K})$ is seen at time periods between $600 \mathrm{~s}$ and $1200 \mathrm{~s}$ is equal for both the positive and negative terminals. The temperature of the positive and negative terminals diverges slightly over time; this divergence is predicted by the model and is a direct result of equations (11) and (12)( 13 ) derived above in section 4.5.1. As a result, this is the first model to predict this behaviour.

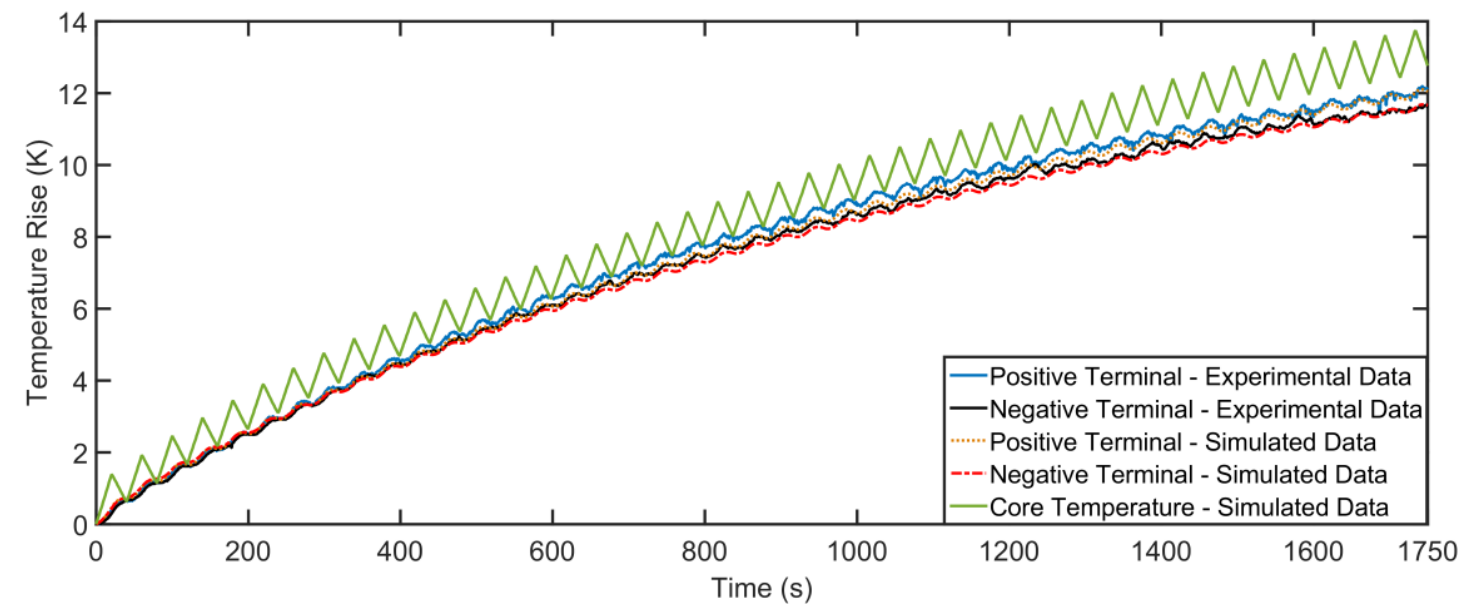

Figure 14: Comparison of temperature rise at the surface and core of the cell when in constant operation, i.e. continuous charge and discharge at $50 \mathrm{~A}$ between $1.2-2.7 \mathrm{~V}$ at $25^{\circ} \mathrm{C}$

The model predicts that the temperature at the core of the cell is consistently higher than at the surface of the cell. Figure 14 shows the increasing divergence between the temperature at the core and at the surface of the cell.

The temperature gradient between the core and surface of the cell does not increase significantly over time because of good thermal conductivity between the current collectors and aluminium can. For heat generated within the carbon electrodes to conduct into the current collectors and subsequently the aluminium can, thermal gradients must exist, however these thermal gradients are supressed when the cell is discharged. Entropic heat generation causes heating on charge and cooling on discharge, and in the cell under study the combination of the ohmic and entropic heat caused by a $50 \mathrm{~A}$ discharge results in a net cooling of the electrodes.

\subsection{Comparison with Existing Works}

\subsubsection{Comparison with Experimental Data}

Gualous et al [18] have inserted thermocouples into a cell and report measurements which show a much larger thermal gradients than predicted by this study; a comparison can be seen in Table 5. This result is expected as inserting thermocouples altered the physical structure of the device, and hence altered its thermal characteristics. The results of Gualous et al have been recreated in the model developed by this study to determine the physical 
changes necessary to account for the differences in thermal characteristics of the cell modified via thermocouple insertion.

\begin{tabular}{|l|c|c|}
\hline $\begin{array}{l}\text { Temperature Gradient } \\
\text { Location }\end{array}$ & $\begin{array}{l}\text { Measurements of } \\
\text { Gualous et al }\left({ }^{\circ} \mathrm{C}\right)\end{array}$ & Predictions of this study $\left({ }^{\circ} \mathrm{C}\right)$ \\
\hline Core to radial edge of jelly-roll & 1 & 0.1 \\
\hline Core of jelly roll to cell surface & Upto 5.4 & Upto 1.2 \\
\hline
\end{tabular}

Table 5: Comparison of temperature gradients predicted by this study with experimental works conducted by Gualous et al [18]

The thermal gradient between the radial edge and core of the jelly-roll can be recreated though elimination of the air-gap between the outer edge of the jelly-roll and the aluminium can. Gualous acknowledges that the jell-roll has been wound manually and that the 'mechanical tension is much smaller', which suggests that the aforementioned air-gap is not present in the cell with thermocouples inserted.

The thermal gradient between the surface and core of the cell can be re-created by greatly reducing the area of connections of the current collector with the terminals. Gualous et al acknowledge that 'current collector contacting is incomplete'. As a result the thermal resistance for some parts of the jelly-roll is greatly increased as heat must conduct through a greater radial distance (in the $x$-direction) or through additional layers (in the $z$-direction) of aluminium, carbon and separator material to reach an area of current collector which is directly connected to a terminal.

\subsubsection{Comparison with Existing Models}

A lumped thermal model as utilised many numerous authors, [18,21,47,48], typically provides a good estimate of the overall temperature rise, however it cannot account for the time taken for heat conduct from the core of the cell to the surface. As a result, the lumped model produces undamped results. A lumped model was generated using identical parameters for heat generation and heat transfer to the environment as the pseudo-3D model. A comparison between the results produced by the lumped thermal model and pseduo-3D model are shown below in Figure 15.

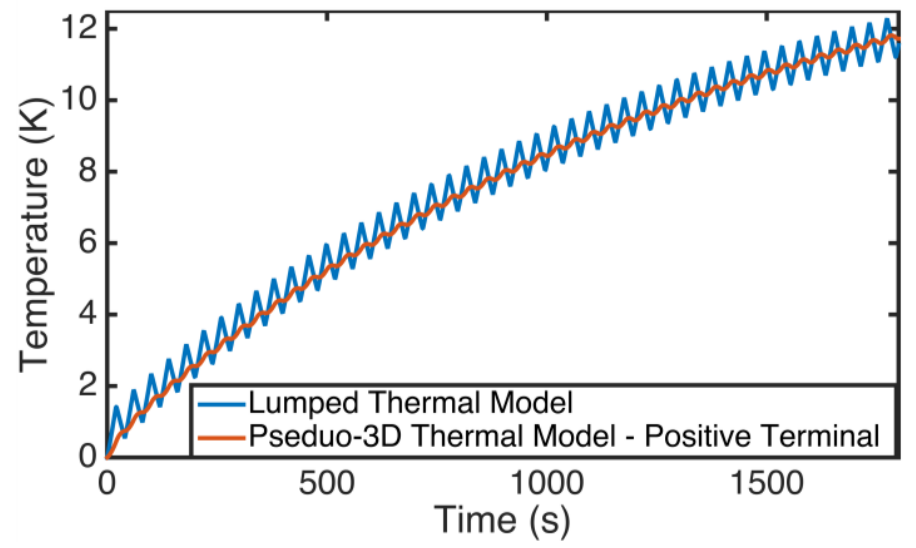

Figure 15: Comparison of temperature rise predicted by the lumped model and pseudo-3D model (positive terminal) when in constant operation, i.e. continuous charge and discharge at $50 \mathrm{~A}$ between $1.2-2.7 \mathrm{~V}$ at $25^{\circ} \mathrm{C}$ 
A lumped thermal model is suitable if only the overall temperature rise is of interest. It cannot predict the temperature of the jelly-roll, and hence will introduce errors into the electrical model. Furthermore, over a single charge event the maximum error is in excess of $200 \%$ (0.98K error).

Gualous et al [22] created a thermal model which considers heat transfer in the axial and radial directions ( $y$ and $z$ directions), but does not consider heat transfer around the spiral of the jelly-roll ( $x$-direction). Their model validation is complete using both a self-generated dataset and one provided by the Paul Scherrer Institute. The internal temperature measurements used for validation are of the central airgap of a Maxwell BCAP010 and a Maxwell BCAP0350 cell. The internal temperature measurements in this study clearly do not show the effects of entropy, which are shown very clearly in a latter study (2011) by the same author [18]. Consequently, the model also does not consider entropic thermal effects. Gualous et al do not show plots that show axial or radial temperature distributions, and the pseudo-3D model developed in this study does not model the central air-gap, hence a meaningful comparison of findings is not possible.

Frivaldsky et al [20] created a 3D thermal model and evaluated the steady-state results to examine the temperature gradients which form. The axial and radial temperature distribution results shown in [20] are very similar to the results produced by the pseudo 3-D model which are shown in Figure 13. The model has no electrical coupling.

\subsection{Conclusions}

An electro-thermal model for an Electrochemical Double Layer Capacitor (EDLC) has been developed to predict the internal temperature of a cell whilst applying pulse loads. The electro-thermal model consists of a coupled electrical model, heat generation model and heat transfer model.

The electrical model is adapted from a generic physically meaningful equivalent circuit model of an EDLC. It is shown that the current density and hence rate of heat generation does not vary significantly throughout the jelly-roll. Therefore it is suitable to assume uniform spatial heat generation within the jelly-roll. The heat generation model considers both irreversible (ohmic) and reversible (entropic) heat generation. Typically entropic heat generation is defined as a bulk value, however in this study entropy was independently calculated for the positive and negative electrodes. It is shown that the entropic heat generated at the positive electrode of a typical commercial EDLC is approximately $40 \%$ greater than that at the negative electrode. Consideration of entropy independently at each electrode was necessary to predict the temperature divergence of the positive and negative electrodes.

A physical pseudo-3D heat transfer model was developed to take advantage of the axisymmetric nature of cylindrical cells and avoid the high computational cost of a true 3D heat transfer model. Unlike other non-truly 3D thermal models, heat transfer is considered in each direction and the rate of heat transfer is 
governed by the geometric and thermal properties of the materials rather than bulk values. Consequently, the predicted radial temperature variation of the developed model show a greater non-linearity than the other non-truly 3D thermal models, which is in line with the predictions of existing 3D thermal models.

The model indicates that under pulse load conditions, a temperature difference in excess of $3.5^{\circ} \mathrm{C}$ can form between the surface of the positive terminal and the jelly-roll, however the temperature gradient across the jelly-roll is small. Therefore, it is important for electrical models to consider the temperature of the active material and not simply the surface of the cell when considering a high current pulse load condition. This is of particular importance in high capacity cells where the ionic resistance is greater than the series resistance. At very low temperatures, an increase of $3.5^{\circ} \mathrm{C}$ can yield a change in resistance of up to $6 \%$ in the resistance value, and up to $15 \%$ in the capacitance value.

\subsection{Acknowledgements}

The authors gratefully acknowledge funding provided by Jaguar Land Rover and the Innovate UK's Knowledge Transfer Partnership scheme award number KTP9095, and the experimental assistance provided by the WMG HVM Catapult centre, and the EPSRC for funding of this work through a Career Acceleration Fellowship for Gregory Offer, award number EP/I00422X/1.

\subsection{References}

[1] A. Burke, Simulations of Plug-in Hybrid Vehicles using Advanced Lithium Batteries and Ultracapacitors on Various Driving Cycles, in: Int. Adv. Mobil. Forum, 2010: pp. 1-13.

[2] R.T. Doucette, M.D. McCulloch, A comparison of high-speed flywheels, batteries, and ultracapacitors on the bases of cost and fuel economy as the energy storage system in a fuel cell based hybrid electric vehicle, J. Power Sources. 196 (2011) 1163-1170. doi:10.1016/j.jpowsour.2010.08.100.

[3] R.A. Dougal, S. Liu, R.E. White, Power and Life Extension of Battery Ultracapacitor Hybrids, IEEE Trans. Components Packag. Technol. 25 (2002) 120-131.

[4] S. Fiorenti, J. Guanetti, Y. Guezennec, S. Onori, Modeling and experimental validation of a Hybridized Energy Storage System for automotive applications, J. Power Sources. 241 (2013) 112-120. doi:10.1016/j.jpowsour.2013.04.017.

[5] C.G. Hochgraf, J.K. Basco, T.P. Bohn, I. Bloom, Effect of ultracapacitormodified PHEV protocol on performance degradation in lithium-ion cells, J. Power Sources. 246 (2014) 965-969. doi:10.1016/j.jpowsour.2012.09.038. 
[6] A. Kuperman, I. Aharon, S. Malki, A. Kara, Design of a Semiactive BatteryUltracapacitor Hybrid Energy Source, IEEE Trans. Power Electron. 28 (2013) 806-815. doi:10.1109/TPEL.2012.2203361.

[7] A. Kuperman, I. Aharon, Battery-ultracapacitor hybrids for pulsed current loads: A review, Renew. Sustain. Energy Rev. 15 (2011) 981-992. doi:10.1016/j.rser.2010.11.010.

[8] 0. Laldin, M. Moshirvaziri, O. Trescases, Predictive Algorithm for Optimizing Power Flow in Hybrid Ultracapacitor/Battery Storage Systems for Light Electric Vehicles, IEEE Trans. Power Electron. 28 (2013) 38823895. doi:10.1109/TPEL.2012.2226474.

[9] R. Kötz, M. Hahn, R. Gallay, Temperature behavior and impedance fundamentals of supercapacitors, J. Power Sources. 154 (2006) 550-555. doi:10.1016/j.jpowsour.2005.10.048.

[10] G. Alcicek, H. Gualous, P. Venet, R. Gallay, A. Miraoui, Experimental study of temperature effect on ultracapacitor ageing, in: 2007 Eur. Conf. Power Electron. Appl., IEEE, 2007: pp. 1-7. doi:10.1109/EPE.2007.4417619.

[11] O. Briat, J.-M. Vinassa, N. Bertrand, H. El Brouji, J.-Y. Delétage, E. Woirgard, Contribution of calendar ageing modes in the performances degradation of supercapacitors during power cycling, Microelectron. Reliab. 50 (2010) 1796-1803. doi:10.1016/j.microrel.2010.07.118.

[12] A. Hammar, P. Venet, R. Lallemand, G. Coquery, G. Rojat, Study of Accelerated Aging of Supercapacitors for Transport Applications, IEEE Trans. Ind. Electron. 57 (2010) 3972-3979. doi:10.1109/TIE.2010.2048832.

[13] W. Lajnef, J.-M. Vinassa, O. Briat, H. El Brouji, S. Azzopardi, E. Woirgard, Quantification of ageing of ultracapacitors during cycling tests with current profile characteristics of hybrid and electric vehicles applications, IET Electr. Power Appl. 1 (2007) 683. doi:10.1049/iet-epa:20070066.

[14] R.K. M Hahn, O Barbieri, JC Sauter, Measurement and estimation of supercapacitor life time, 2004.

[15] B.E. Conway, Electrochemical Supercapacitors, Springer; 1999 edition (April 30, 1999), 1999.

[16] A. d'Entremont, L. Pilon, First-order thermal model of commercial EDLCs, Appl. Therm. Eng. 67 (2014) 439-446. doi:10.1016/j.applthermaleng.2014.03.061.

[17] Y. Parvini, J.B. Siegel, A.G. Stefanopoulou, A. Vahidi, Preliminary results on identification of an electro-thermal model for low temperature and high 
power operation of cylindrical double layer ultracapacitors, in: $2014 \mathrm{Am}$. Control Conf., IEEE, 2014: pp. 242-247. doi:10.1109/ACC.2014.6859394.

[18] H. Gualous, H. Louahlia, R. Gallay, Supercapacitor Characterization and Thermal Modelling With Reversible and Irreversible Heat Effect, IEEE Trans. Power Electron. 26 (2011) 3402-3409. doi:10.1109/TPEL.2011.2145422.

[19] D.H. Lee, U.S. Kim, C.B. Shin, B.H. Lee, B.W. Kim, Y.-H. Kim, Modelling of the thermal behaviour of an ultracapacitor for a $42-\mathrm{V}$ automotive electrical system, J. Power Sources. 175 (2008) 664-668. doi:10.1016/j.jpowsour.2007.09.081.

[20] M. Frivaldsky, J. Cuntala, P. Spanik, Simple and accurate thermal simulation model of supercapacitor suitable for development of module solutions, Int. J. Therm. Sci. 84 (2014) 34-47. doi:10.1016/j.ijthermalsci.2014.04.005.

[21] A. Berrueta, I. San Martín, A. Hernández, A. Ursúa, P. Sanchis, Electrothermal modelling of a supercapacitor and experimental validation, J. Power Sources. 259 (2014) 154-165. doi:10.1016/j.jpowsour.2014.02.089.

[22] H. Gualous, H. Louahlia-Gualous, R. Gallay, A. Miraoui, Supercapacitor Thermal Modeling and Characterization in Transient State for Industrial Applications, IEEE Trans. Ind. Appl. 45 (2009) 1035-1044. doi:10.1109/TIA.2009.2018879.

[23] M.W. Verbrugge, P. Liu, Microstructural Analysis and Mathematical Modeling of Electric Double-Layer Supercapacitors, J. Electrochem. Soc. 152 (2005) D79. doi:10.1149/1.1878052.

[24] S. Allu, B. Velamur Asokan, W.A. Shelton, B. Philip, S. Pannala, A generalized multi-dimensional mathematical model for charging and discharging processes in a supercapacitor, J. Power Sources. 256 (2014) 369-382. doi:10.1016/j.jpowsour.2014.01.054

[25] R. Drummond, D.A. Howey, S.R. Duncan, Low-order mathematical modelling of electric double layer supercapacitors using spectral methods, J. Power Sources. 277 (2015) 317-328. doi:10.1016/j.jpowsour.2014.11.116.

[26] S. Buller, E. Karden, D. Kok, R.W. De Doncker, Modeling the dynamic behavior of supercapacitors using impedance spectroscopy, Ind. Appl. IEEE Trans. 38 (2001) 1622-1626. http://ieeexplore.ieee.org/xpls/abs_all.jsp?arnumber=955972 (accessed December 5, 2013).

[27] J. Black, H.A. Andreas, Prediction of the self-discharge profile of an electrochemical capacitor electrode in the presence of both activation- 
controlled discharge and charge redistribution, 195 (2010) 929-935. doi:10.1016/j.jpowsour.2009.08.040.

[28] D. Torregrossa, M. Bahramipanah, E. Namor, R. Cherkaoui, M. Paolone, Improvement of Dynamic Modeling of Supercapacitor by Residual Charge Effect Estimation, IEEE Trans. Ind. Electron. 61 (2014) 1345-1354. doi:10.1109/TIE.2013.2259780.

[29] W. Lajnef, J.-M. Vinassa, O. Briat, S. Azzopardi, E. Woirgard, Characterization methods and modelling of ultracapacitors for use as peak power sources, J. Power Sources. 168 (2007) 553-560. doi:10.1016/j.jpowsour.2007.02.049.

[30] J. Black, H. a. Andreas, Effects of charge redistribution on self-discharge of electrochemical capacitors, Electrochim. Acta. 54 (2009) 3568-3574. doi:10.1016/j.electacta.2009.01.019.

[31] N. Devillers, S. Jemei, M.-C. Péra, D. Bienaimé, F. Gustin, Review of characterization methods for supercapacitor modelling, J. Power Sources. 246 (2014) 596-608. doi:10.1016/j.jpowsour.2013.07.116.

[32] R. De Levie, On porous electrodes in electrolyte solutions-IV, Electrochim. Acta. 8 (1963). http://www.sciencedirect.com/science/article/pii/0013468664850155 (accessed February 20, 2014).

[33] W. Lajnef, J.-M. Vinassa, O. Briat, S. Azzopardi, E. Woirgard, Characterization methods and modelling of ultracapacitors for use as peak power sources, J. Power Sources. 168 (2007) 553-560. doi:10.1016/j.jpowsour.2007.02.049.

[34] V. Musolino, L. Piegari, E. Tironi, New Full-Frequency-Range Supercapacitor Model With Easy Identification Procedure, IEEE Trans. Ind. Electron. 60 (2013) 112-120. doi:10.1109/TIE.2012.2187412.

[35] C. Merlet, B. Rotenberg, P. a Madden, P.-L. Taberna, P. Simon, Y. Gogotsi, et al., On the molecular origin of supercapacitance in nanoporous carbon electrodes., Nat. Mater. 11 (2012) 306-10. doi:10.1038/nmat3260.

[36] M. Deschamps, E. Gilbert, P. Azais, E. Raymundo-Piñero, M.R. Ammar, P. Simon, et al., Exploring electrolyte organization in supercapacitor electrodes with solid-state NMR., Nat. Mater. 12 (2013) 351-8. doi:10.1038/nmat3567.

[37] G. Feng, J. Huang, B.G. Sumpter, V. Meunier, R. Qiao, Structure and dynamics of electrical double layers in organic electrolytes., Phys. Chem. Chem. Phys. 12 (2010) 5468-79. doi:10.1039/c000451k.

[38] John M. Miller, Ultracapacitor Appliations, IET, 2011. 
[39] B. Wu, M.A. Parkes, V. Yufit, L. De Benedetti, S. Veismann, C. Wirsching, et al., Design and testing of a $9.5 \mathrm{kWe}$ proton exchange membrane fuel cellsupercapacitor passive hybrid system, Int. J. Hydrogen Energy. 39 (2014) 7885-7896. doi:10.1016/j.ijhydene.2014.03.083.

[40] M. Kaus, J. Kowal, D.U. Sauer, Modelling the effects of charge redistribution during self-discharge of supercapacitors, Electrochim. Acta. 55 (2010) 7516-7523. doi:10.1016/j.electacta.2010.01.002.

[41] D.H. Lee, U.S. Kim, C.B. Shin, B.H. Lee, B.W. Kim, Y.-H. Kim, Modelling of the thermal behaviour of an ultracapacitor for a $42-\mathrm{V}$ automotive electrical system, J. Power Sources. 175 (2008) 664-668. doi:10.1016/j.jpowsour.2007.09.081.

[42] O.S. Burheim, M. Aslan, J.S. Atchison, V. Presser, Thermal conductivity and temperature profiles in carbon electrodes for supercapacitors, J. Power Sources. 246 (2014) 160-166. doi:10.1016/j.jpowsour.2013.06.164.

[43] H.H. Hauge, V. Presser, O. Burheim, In-situ and ex-situ measurements of thermal conductivity of supercapacitors, Energy. 78 (2014) 373-383. doi:10.1016/j.energy.2014.10.022.

[44] J. Schiffer, D. Linzen, D.U. Sauer, Heat generation in double layer capacitors, J. Power Sources. 160 (2006) 765-772. doi:10.1016/j.jpowsour.2005.12.070.

[45] Maxwell Technologies, Maxwell K2 Datasheet, n.d. http://www.maxwell.com/images/documents/K2Series_DS_1015370_5_2 0141104.pdf (accessed July 20, 2015).

[46] Ioxus, Ioxus iCap Datasheet, n.d. http://www.ioxus.com/wpcontent/uploads/2015/01/DataSheet_Ioxus_60mm_141207.pdf (accessed July 20, 2015).

[47] M. Al Sakka, H. Gualous, J. Van Mierlo, H. Culcu, Thermal modeling and heat management of supercapacitor modules for vehicle applications, J. Power Sources. 194 (2009) 581-587. doi:10.1016/j.jpowsour.2009.06.038.

[48] A. Hijazi, P. Kreczanik, E. Bideaux, P. Venet, G. Clerc, M. Di Loreto, Thermal Network Model of Supercapacitors Stack, IEEE Trans. Ind. Electron. 59 (2012) 979-987. doi:10.1109/TIE.2011.2158769. 